\title{
Justicia restaurativa y reparación: desafíos de la JEP frente a una relación en construcción*
}

Restorative Justice and Reparation: Challenges of the Special Jurisdiction for Peace Before a Relationship under Construction

\author{
Juana Acosta-López ${ }^{a}$ \\ Universidad de La Sabana, Colombia \\ juanacl@unisabana.edu.co \\ ORCID: https://orcid.org/0000-0002-1973-6777 \\ Cindy Vanessa Espitia Murcia \\ Universidad de La Sabana, Colombia \\ ORCID: https://orcid.org/0000-0002-7510-1856
}

DOI: https://doi.org/10.11144/Javeriana.vj69.jrrd

Fecha de recepción: 07 Octubre 2019

Fecha de aprobación: 29 Noviembre 2019

Fecha de publicación: 30 Junio 2020

\section{Resumen:}

La justicia restaurativa constituye un paradigma orientador de todo el Sistema Integral de Verdad, Justicia, Reparación y No Repetición. En la Jurisdicción Especial para la Paz, el principio no sólo irradia las sanciones propias y la condicionalidad, sino que cada etapa del procedimiento debe guardar estricta coherencia con tal paradigma y con sus fines: la reparación de las víctimas, la reconciliación y la reconstrucción del tejido social. Sin embargo, y a pesar de su importancia, aún existen importantes vacíos sobre el alcance del principio y sobre su relación con los demás componentes del modelo de justicia transicional. En este sentido, en el presente artículo de reflexión, se efectúa una revisión del concepto de justicia restaurativa y de su relación con otros componentes, especialmente el de reparación, desde una perspectiva analítica y propositiva. Asimismo, se plantean los retos de Colombia respecto de la materialización del principio, especialmente para la JEP. Las propuestas de las autoras, lejos de constituir fórmulas mágicas, plantean discusiones y debates que deben ser abordados, para lograr que este paradigma orientador contribuya a la construcción de paz en Colombia.

Palabras clave: justicia restaurativa, reparación, justicia transicional, Jurisdicción Especial para la Paz, integralidad.

\section{Abstract:}

Restorative justice is a guiding principle for the entire Integral System of Truth, Justice, Reparation and Non-Repetition. In the Special Jurisdiction for Peace, the principle radiates sanctions and conditionality, and each stage of the procedure must be strictly consistent with such paradigm and its purposes: victim's reparation, reconciliation and the rebuilding of social structures. However, despite its importance, there are still critical gaps regarding the scope of the principle and its relationship with other components of the transitional justice model. Therefore, the paper analyzes the concept of restorative justice and its relationship with other components, particularly reparation from an analytical perspective. It also raises Colombia's challenges regarding the materialization of the principle, especially for the SJP. The proposals, far from constituting magical formulas, raise discussions and debates that must be addressed, to ensure that this guiding paradigm contributes to the construction of peace in Colombia.

Keywords: restorative justice, reparation, transitional justice, Special Jurisdiction for Peace, integrality.

\section{Introducción}

El Acuerdo de Paz y el marco jurídico que ha facilitado su implementación ha reconocido a la justicia restaurativa (JR) como (i) un principio o paradigma orientador ${ }^{[1]}$ (ii) que irradia todo el modelo de justicia transicional $(\mathrm{JT})^{[2]}$ y (iii) que tiene varios fines como la transformación de las causas estructurales

Notas de autor

a Autora de correspondencia. Correo electrónico: juanacl@unisabana.edu.co 
que consolidaron un escenario de victimización ${ }^{[3]}$, la garantía de la no repetición de las violaciones y, especialmente, la reparación a las víctimas y el resarcimiento del daño causado en el marco de las violaciones perpetradas en su contra ${ }^{[4]}$.

Sin embargo, pese a la fuerza transversal de la justicia restaurativa, el marco constitucional y legal que ha dotado de sustento el funcionamiento de la JEP no resulta lo suficientemente claro para determinar la forma en la que se materializarán los mandatos normativos relacionados con dicho principio. En particular, por un lado, existen varios vacíos frente a la implementación del principio de justicia restaurativa en las distintas etapas del procedimiento y, por el otro, no hay certeza sobre las fórmulas que se implementarán para articular la aplicación de las sanciones restaurativas con las demás vías de reparación existentes en Colombia y aplicables a asuntos que también se encuentran amparados por la competencia de la JEP.

Definir cómo se llenarán de contenido los vacíos existentes resulta determinante, especialmente si se tiene en cuenta que la reparación que pretende garantizarse a través de la JEP, no podrá entenderse de manera aislada, sin considerar la existencia de otras vías de reparación que han sido creadas en el nivel nacional. Esto se debe a que (i) la reparación a las víctimas constituye el norte de la justicia restaurativa, no sólo de conformidad con su abordaje doctrinal ${ }^{[5]}$, sino también con su desarrollo legal ${ }^{[6]}$ y jurisprudencial en Colombia ${ }^{[7]}$, y (ii) el principio de integralidad y coordinación entre diferentes mecanismos para garantizar los derechos a la verdad, justicia, reparación y no repetición de las víctimas ${ }^{[8]}$ han sido reconocidos como elementos transversales del modelo de justicia transicional ${ }^{[9]}$.

A fin de analizar estos retos vigentes en la aplicación de la justicia restaurativa durante el trámite ante la JEP desde una mirada propositiva, primero se abordarán las limitaciones y aportes de la concepción restaurativa de la justicia en un modelo de justicia transicional. Segundo, se efectuará una delimitación de los conceptos de justicia restaurativa y reparación en contextos de transición y de las relaciones de interdependencia que pueden generarse entre aquellos. Tercero, se analizarán las vías concebidas en el marco jurídico colombiano para aplicar estos dos conceptos, y cuarto, se propondrán algunas alternativas que pueden contribuir a enfrentar los principales desafíos en la materialización de la justicia restaurativa y su relación con otros componentes del modelo colombiano que comparten algunas de sus finalidades.

\section{La justicia restaurativa en un sistema de justicia transicional: divergencias, convergencias y aportes}

Abordar la justicia restaurativa en el marco de la justicia transicional requiere partir de cuatro premisas necesarias: (i) la JR no se circunscribe exclusivamente al campo de la JT; (ii) desde la concepción de estos dos paradigmas se presentan discrepancias conceptuales y materiales que inciden en el alcance de la relación que surja entre aquellos; (iii) la JR y JT sí comparten finalidades centrales y (iv) en consecuencia, la justicia restaurativa puede aportar a los fines de la transición desde su concepción como valor y como proceso.

En primer lugar, si bien es cierto que se ha ido consolidando un fuerte movimiento doctrinal que aborda una concepción integradora de la justicia restaurativa y la justicia transicional ${ }^{[10]}$, no puede pasarse por alto que la JR surgió como respuesta a una percepción de inefectividad e injusticia del sistema penal convencional ${ }^{[11]} \mathrm{y}$ como un paradigma alternativo en el abordaje del delito y los desórdenes sociales ${ }^{[12]}$. La propuesta de la justicia restaurativa consiste en superar la exclusiva dimensión retributiva del derecho penal y otorgar prioridad no sólo al daño causado y a los sujetos afectados\#víctimas, comunidades e, incluso, victimarios\#, sino también a la reconciliación de aquellos ${ }^{[13]}$. Así pues, el campo de acción de la JR es mucho más amplio y, en la práctica, tanto en Colombia ${ }^{[14]}$ como en otros Estados ${ }^{[15]}$ se ha implementado en escenarios que no necesariamente coinciden con la JT. 
En segundo lugar, justamente por cuanto la JR y la JT se han consolidado como áreas con un ámbito propio, existen divergencias relacionadas con (i) su origen, (ii) el marco jurídico que las regula; (iii) su aplicación; (iv) su temporalidad; y (v) el abordaje que dan a la sanción que, bajo ninguna circunstancia, pueden ser pasadas por alto. El siguiente cuadro resume algunas de las principales diferencias:

TABLA 1

Divergencias de la justicia transicional y la justicia restaurativa

\begin{tabular}{|c|c|c|}
\hline & Justicia transicional & Justicia restaurativa \\
\hline Origen & $\begin{array}{l}\text { Surge para hacer frente a un } \\
\text { pasado de violaciones a gran } \\
\text { escala y hacer tránsito a un } \\
\text { escenario de rendición de } \\
\text { cuentas, reconciliación social y } \\
\text { respeto por los derechos } \\
\text { humanos }\end{array}$ & $\begin{array}{l}\text { Surge como alternativa al } \\
\text { sistema penal convencional, } \\
\text { como reacción a una } \\
\text { dimensión retributiva, que } \\
\text { pone su foco en el victimario, } \\
\text { en el crimen y el castigo }{ }^{[17]} \text {. }\end{array}$ \\
\hline $\begin{array}{l}\text { Ambito de } \\
\text { aplicación }\end{array}$ & $\begin{array}{l}\text { Ha sido concebida para } \\
\text { escenarios de violaciones } \\
\text { masivas a los derechos } \\
\text { humanos }^{[18]}\end{array}$ & $\begin{array}{l}\text { Fue concebida para } \\
\text { escenarios de normalidad. } \\
\text { Criminalidad a pequeña } \\
\text { escala }{ }^{[19]}\end{array}$ \\
\hline Temporalidad & Transitoria $^{[20]}$ & Permanente $^{[21]}$ \\
\hline $\begin{array}{l}\text { Fuentes del derecho } \\
\text { internacional que la } \\
\text { delimitan }\end{array}$ & $\begin{array}{l}\text { No es un cuerpo internacional } \\
\text { autocontenido, pero varias } \\
\text { fuentes de diferentes sistemas } \\
\text { han aportado a su } \\
\text { consolidación. En particular, el } \\
\text { derecho internacional de los } \\
\text { derechos humanos, el derecho } \\
\text { internacional humanitario y el } \\
\text { derecho penal internacional. }\end{array}$ & $\begin{array}{l}\text { En proceso de construcción. } \\
\text { Se cuenta con informes y } \\
\text { resoluciones de la UNODC y } \\
\text { el Consejo Económico y } \\
\text { Social. }\end{array}$ \\
\hline $\begin{array}{l}\text { Concepción de la } \\
\text { sanción }\end{array}$ & $\begin{array}{l}\text { La JT, en cuanto se desarrolla } \\
\text { bajo obligaciones } \\
\text { internacionales reforzadas - } \\
\text { por la naturaleza de las } \\
\text { vulneraciones que usualmente } \\
\text { son objeto de conocimiento } \\
\text { por los órganos internos-, } \\
\text { requiere de una sanción } \\
\text { efectiva. No puede apartarse } \\
\text { completamente del } \\
\text { componente retributivo }\end{array}$ & $\begin{array}{l}\text { Énfasis en (i) daños y en su } \\
\text { correspondiente reparación; } \\
\text { (ii) la reconstrucción del } \\
\text { tejido social y (iii) la } \\
\text { reintegración a la sociedad } \\
\text { [23] }\end{array}$ \\
\hline
\end{tabular}

Fuente: elaboración propia

Debido a estas diferencias planteadas entre la JR y la JT en la tabla 1, órganos internacionales ${ }^{[24]}$, tribunales internos ${ }^{[25]}$ y doctrinantes ${ }^{[26]}$ han resaltado que (i) la JR no puede constituir el único paradigma aplicable en una transición, por cuanto en este escenario, se avoca el conocimiento de graves violaciones a los derechos humanos - de las cuales se han derivado obligaciones internacionales concretas para los Estados-, y (ii) por lo tanto, deberá promoverse una armonización entre la justicia restaurativa y la retributiva en estos contextos.

En tercer lugar, si bien se ha indicado que la JR no puede ser el único paradigma aplicable en un modelo de JT, esto no significa que aquella no pueda coadyuvar a los procesos de transición, especialmente teniendo presente que estos dos campos comparten de manera parcial un punto central: sus fines ${ }^{[27]}$. Así pues, tanto la JR como la JT persiguen, de forma concomitante, la reintegración de los victimarios, la reconstrucción del tejido social, la reconciliación y, especialmente, la reparación de las víctimas y las comunidades afectadas ${ }^{[28]}$. 
Por último, dada esta convergencia en los fines perseguidos por la JT y la JR, pueden identificarse importantes aportes de la JR a procesos de transición, que podrían ser sistematizados, como lo ha hecho Declan Roche ${ }^{[29]}$, en dos categorías: por un lado, la justicia restaurativa como un conjunto de valores y, por el otro, como un conjunto de procesos.

Desde la perspectiva de la JR como conjunto de valores, este paradigma aporta concepciones a un proceso de transición como (i) la centralidad no sólo de las víctimas, sino también de las comunidades afectadas; (ii) el diálogo como requisito para el perdón ${ }^{[30]}$; (iii) la verdad como construcción colectiva y dialógica; (iv) la restauración del daño como eje de toda actuación y presupuesto para la garantía de la justicia y (v) la reconciliación como fundamento de la no repetición ${ }^{[31]}$.

Estos valores relacionados directamente con la garantía de la verdad, la justicia, la reparación y la no repetición, resultan fundamentales para un escenario de transición, teniendo presente que sobre tales derechos se ha consolidado el desarrollo de la JT en el derecho internacional ${ }^{[32]}$.

Desde la perspectiva procesal, la JR aporta a los contextos de transición (i) la importancia de articular la fase de reintegración a todo procedimiento que se surta en el marco de la administración de justicia; (ii) la apertura de escenarios para la reconstrucción de la verdad y la memoria que recoja las voces de varios sectores afectados; (iii) la definición de espacios de participación de las víctimas, comunidades y victimarios en los procesos no sólo para coadyuvar a un proceso de reconciliación, sino, especialmente, para dotar de verdadero contenido a esa pretensión de reparación que reside en las raíces de este paradigma, y (iv) el reconocimiento de cada etapa como una oportunidad para restaurar el daño ${ }^{[33]}$.

Como se profundizará más adelante, es justamente este legado de la justicia restaurativa \#en sus dos dimensiones\# el que ha buscado ser implementado en Colombia en el marco del Sistema Integral de Verdad, Justicia, Reparación y No Repetición (SIVJRNR), que busca dar cumplimiento a las obligaciones internacionales y recoger varias lecciones de otros procesos de transición que también aplicaron la JR ${ }^{[34]}$.

\section{Aproximación conceptual y complementariedad entre la justicia restaurativa y la reparación en contextos de transición}

Teniendo presente que la justicia restaurativa, concebida como principio orientador de la $\mathrm{JEP}^{[35]}$, tiene como propósito resarcir el daño de las víctimas y que, adicionalmente, se ha contemplado el derecho y deber a la reparación en el derecho internacional ${ }^{[36]}$ y el marco jurídico colombiano ${ }^{[37]}$-en contextos de transición ${ }^{[38]}$ - sin que sea clara la forma en que aquellos componentes interactuarán, a continuación se presentará una delimitación conceptual entre estos dos conceptos -JR y reparación- y una aproximación a sus complementariedades.

\section{Una aproximación a la justicia restaurativa}

La JR constituye un término desarrollado en el marco del derecho penal que aún se encuentra en proceso de construcción y sobre el cual aún existe un álgido debate ${ }^{[39]}$. No obstante, usualmente se ha concebido como un paradigma ${ }^{[40]}$, un conjunto de procesos ${ }^{[41]}$ o de valores ${ }^{[42]}$, que tiene varios propósitos, entre los que se encuentran: (i) resarcir el daño causado como consecuencia de un ilícito; (ii) reintegrar a quienes causaron tal perjuicio; (iii) transformar estructuras sociales; (iv) reconstruir el tejido social, y (iv) reconciliar a las partes en controversia ${ }^{[43]}$.

Respecto de tal dimensión transformadora, la Oficina de las Naciones Unidas contra la Droga y el Delito ha señalado que el cambio estructural debido a la implementación de programas restaurativos, se produce al 
menos en tres niveles. En primer lugar, una transformación interna, materializada en participantes -víctimas y victimarios-; en segundo lugar, una intermedia, en círculos cercanos a los participantes y comunidades afectadas y, por último, una externa, en la que se busca resolver las causas subyacentes del crimen ${ }^{[44]}$.

A fin de cumplir con tales propósitos, el paradigma de la JR demanda de la comparecencia voluntaria del victimario y de su reconocimiento de responsabilidad. Una vez se cumplan estos presupuestos, el victimario deberá involucrarse en el resarcimiento del daño causado a la víctima y a la comunidad afectada, a fin de que puedan sentarse los cimientos para promover la reconciliación entre las partes ${ }^{[45]}$. En tales procesos y, en particular, en la determinación de los mecanismos para resarcir los daños causados, se ha resaltado la importancia de que víctimas, aquellos que han sido identificados como 'victimarios' y comunidades involucradas participen, tanto en la planeación como en la ejecución de las medidas correspondientes ${ }^{[46]}$.

Teniendo presente lo anterior, es posible señalar que la JR no sólo se materializa en un resultado -esto es, la posible ejecución de mecanismos de resarcimiento a las víctimas o a las comunidades afectadas-, sino en el mismo proceso. Así pues, se concibe que cada una de las etapas -desde la apertura de los escenarios de diálogo hasta la realización de las medidas restaurativas- constituyen una oportunidad para reivindicar a las víctimas $^{[47]}$.

\section{Una aproximación a la reparación en contextos de transición}

La reparación en escenarios de transición ha sido concebida desde una doble perspectiva. Por un lado, como un derecho de las víctimas que se deriva del derecho al acceso a la justicia, y, por otro lado, como una obligación de garantía en cabeza del Estado ${ }^{[48]}$. El ex Relator de las Naciones Unidas, Pablo de Greiff resaltó que a través de la reparación no sólo se busca resarcir el daño causado y estimular la reconciliación, sino también reconocer a las víctimas directas, indirectas, individuales o colectivas ${ }^{[49]}$ como titulares de derecho y restablecer su confianza en las instituciones del Estado ${ }^{[50]}$.

Ahora bien, la reparación en el contexto analizado en el presente artículo, al ser considerada como un deber del Estado y como un derecho que se desprende del acceso a la justicia, requiere de la participación del Estado, bien sea a través de la disposición de recursos internos para su garantía o por medio del resarcimiento directo, en los casos que así proceda ${ }^{[51]}$. En tal sentido, el resarcimiento no sólo puede recaer en cabeza de un individuo causante del daño, sino también en el Estado como ente abstracto (i) ante los supuestos en los que se acredite su responsabilidad ${ }^{[52]}$ o (ii) en escenarios como el de Colombia, Perú, Filipinas y Túnez en los que han sido los propios Estados los que han asumido el deber de reparar a víctimas de graves violaciones a los derechos humanos. Esto ocurre especialmente bajo el principio de solidaridad en contextos de vulneraciones masivas, a pesar de que las conductas no sean atribuibles a sus agentes estatales ${ }^{[53]}$.

Ahora bien, es preciso resaltar que, tal y como ha sido desarrollada en el en el marco de la reparación hasta el momento, se apunta a promover únicamente la participación de las víctimas, en los casos en los que así haya sido solicitado, y el rol de los victimarios, de existir, usualmente se limita a la ejecución de los actos -como los reconocimientos de responsabilidad- ${ }^{[54]}$.

Por último, órganos internacionales y nacionales han destacado que los programas de reparación no deben limitarse al componente compensatorio, por el contrario, deberán apelar a la integralidad, en tanto tendrá que comprender medidas de compensación, restitución, rehabilitación y satisfacción ${ }^{[55]}$.

\section{JR y reparación: puntos de encuentro}

Tras efectuar una aproximación conceptual a la justicia restaurativa y al derecho a la reparación en contextos de transición, por un lado, se identifican como puntos de encuentro (i) el propósito de ambos campos de 
remediar el daño causado a las víctimas; (ii) la concepción de las víctimas como destinatarias de las medidas a adoptar y como sujetos centrales del proceso cuya voz debe ser escuchada y (iii) el rol que juegan los individuos que causaron el perjuicio en su correspondiente reparación ${ }^{[56]}$.

Por otro lado, puede señalarse que entre estos dos conceptos se configura una verdadera relación de complementariedad de doble vía. Existe una cualificación y coadyuvancia mutua en el cumplimiento de los propósitos y de los fines perseguidos por ambos campos (figura 1).

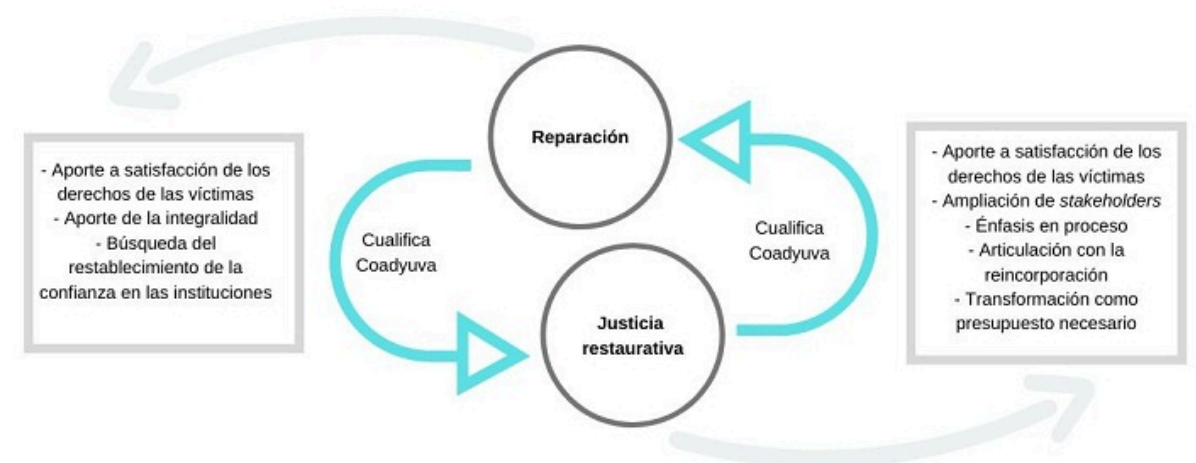

FIGURA 1.

Relación de complementariedad entre la reparación y la JR

Fuente: elaboración propia

En tal sentido, la justicia restaurativa no sólo aporta al cumplimiento de los fines de la reparación, en tanto también persigue el resarcimiento del daño y la reconciliación, sino que la cualifica como conjunto de valores y procesos, ya que (i) amplía los sujetos que deben hacer parte del proceso de planeación y ejecución de las medidas a adoptar; (ii) aborda a nuevos destinatarios cuya contribución resulta necesaria para sentar las bases de la reconciliación; (iii) permite la articulación con la reincorporación; (iv) concibe como presupuesto innegociable la formulación de estrategias para transformar las estructuras sociales que favorecieron la consolidación de un escenario de victimización y (v) promueve una coherencia entre cada etapa del proceso con los propósitos de la intervención.

Este mismo ejercicio puede realizarse frente a la reparación en relación con la JR, pues aquella no sólo persigue la finalidad de resarcir un perjuicio, sino que también la cualifica en tanto (i) aporta una visión holística e integral de la reparación y (ii) promueve un restablecimiento de la confianza entre las víctimas y el Estado. 
Sobre esta relación de complementariedad en beneficio no sólo de las víctimas sino también de la sociedad misma se estará profundizando en el presente artículo, de cara al proceso de implementación del modelo de justicia transicional, concebido en el Acuerdo Final de Paz entre el Gobierno Nacional y las FARC.

\section{La JR y la reparación en el modelo de justicia transicional en Colombia}

Habiendo efectuado una aproximación conceptual de la JR y de la reparación en escenarios de transición, se procederá a (i) delimitar el marco jurídico que desarrolla estos dos campos en la transición en Colombia; (ii) identificar las tensiones entre los diversos mecanismos creados para remediar o resarcir el daño causado a las víctimas en el marco del conflicto armado, y (iii) definir los principales vacíos que se derivan de la materialización de la JR.

\section{Justicia restaurativa y reparación en el modelo de justicia transicional colombiano}

El modelo de justicia transicional en Colombia desarrolla la aplicación de la JR y la reparación en el marco del proceso de construcción de paz. En el presente aparte, se abordarán brevemente las bases que otorgan sustento a estos dos elementos.

\section{La JR como principio transversal en el modelo de justicia transicional}

La JR ha sido concebida como un paradigma orientador de la JEP ${ }^{[57]}$ y como uno de los objetivos que persigue este órgano en cumplimiento de su mandato ${ }^{[58]}$. De conformidad con el complejo sistema de fuentes que dan vida al modelo de JT colombiano, a este paradigma se le atribuyen funciones como (i) la restauración del

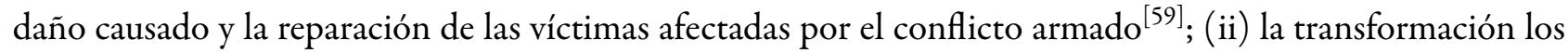
contextos de exclusión social que provocaron la victimización ${ }^{[60]}$; (iii) la reconciliación y el restablecimiento de las relaciones de los actores sociales ${ }^{[61]}$; (iv) la garantía de la no repetición y la protección de los derechos de las generaciones futuras ${ }^{[62]}$; (v) el fortalecimiento del proceso de reincorporación ${ }^{[63]}$; y (vi) el aporte a la construcción dialógica de la verdad ${ }^{[64]}$.

Los destinatarios de la aplicación del paradigma de acuerdo al modelo de JT colombiano corresponden de manera prevalente a las víctimas del conflicto armado, individuales y colectivas ${ }^{[65]}$. En todo caso, también se dispone su impacto en las comunidades, en la sociedad ${ }^{[66]}$ y en los mismos comparecientes.

Sobre este último punto, la Sala de Definición de Situaciones Jurídicas de la JEP señaló que el paradigma de la justicia restaurativa debe propender porque los victimarios

adquieran una comprensión profunda de la violencia de la cual fueron artífices y por esa vía, surja el reconocimiento de las responsabilidades (...) [y] se comprometan en forma efectiva con la reparación a las víctimas, la implementación de medidas eficaces de no repetición y el esclarecimiento de la verdad ${ }^{[67]}$.

Ahora bien, al ser considerado como un paradigma orientador, su materialización en la JEP ha sido definida en tres escenarios: (i) en las diferentes etapas del proceso; (ii) en el sistema de sanciones propias, con un contenido restaurativo y (iii) en el sistema de condicionalidad. 


\section{La JR en el procedimiento ante la JEP}

De conformidad con el modelo de justicia transicional colombiano, la JR debe irradiar el procedimiento surtido ante la JEP y, por lo tanto, cada etapa del proceso debe ser concebida como una oportunidad para reparar a las víctimas y restaurar su daño, además de promover la reconciliación, la reincorporación y la no repetición, entre otras finalidades ${ }^{[68]}$.

En este contexto, la Ley de Procedimiento de la JEP y la Ley Estatutaria conciben de forma expresa la aplicación del principio de JR (i) en la formulación y aprobación del proyecto de sanción restaurativa -en el caso de las sanciones propias ${ }^{[69]}$; (ii) en la realización de la audiencia pública de reconocimiento de verdad por parte de los comparecientes ${ }^{[70]}$; (iii) en el desarrollo de la audiencia restaurativa, en los casos de reconocimiento tardío de responsabilidad, pero previo a la iniciación del juicio oral ${ }^{[71]}$; (iv) en el procedimiento que se surte ante la Sala de Definición de Situaciones Jurídicas y, en particular, el rol que se otorga a ésta de promover el diálogo entre los comparecientes y los intervinientes para fortalecer la reconciliación y la reparación ${ }^{[72]}$; y (v) en el mandato otorgado a la Salas y Secciones de adoptar las medidas para la "armonización y sanación individual, colectiva y territorial" y la construcción de acuerdos entre las partes, en todas las fases del procedimiento ${ }^{[73]}$.

Ahora bien, aunque no se señala de forma expresa en el marco jurídico analizado, tras una aplicación no sólo de la concepción de la JR como principio en el modelo JT colombiano sino también de su contenido inherente \#desarrollado previamente en la aproximación conceptual\# es posible señalar que su aplicación también debe extenderse a etapas como (i) la acreditación de la calidad de víctimas ante la JEP ${ }^{[74]}$; (ii) la presentación de informes por parte de organizaciones de víctimas ${ }^{[75]}$; (iii) la comunicación de la sentencia en el proceso en el que existe reconocimiento de responsabilidad ${ }^{[76]}$; (iv) las audiencias públicas preparatorias y de juzgamiento, adelantadas ante la Sección correspondiente, debido a que se abre la oportunidad para un reconocimiento de responsabilidad tardío por parte de los comparecientes ${ }^{[77]}$, y (v) el mecanismo de monitoreo y supervisión del cumplimiento de las sanciones propias ${ }^{[78]}$, entre otras.

\section{La justicia restaurativa en el régimen de condicionalidad}

El régimen de condicionalidad también ha sido concebido como un eje ${ }^{[79]}$ y principio $^{[80]}$ del SIVJRNR, en tanto armoniza la aplicación de todos los beneficios concebidos en el Sistema con la garantía de los derechos de las víctimas a la verdad, justicia, reparación y a la no repetición. De conformidad con el marco jurídico que ha desarrollado este principio, (i) el otorgamiento de tratamientos especiales está supeditado, en términos generales ${ }^{[81]}$, a la contribución de los beneficiarios o potenciales beneficiarios a la verdad plena, la reparación, la no repetición de las víctimas ${ }^{[82]}$ y la búsqueda de personas desaparecidas ${ }^{[83]}$; (ii) el régimen de condicionalidad aplica a los titulares de tratamientos especiales, con independencia de si se trata de desmovilizados de las FARC ${ }^{[84]}$, miembros de la fuerza pública ${ }^{[85]}$ o terceros ${ }^{[86]}$; (iii) la verificación del cumplimiento de los requisitos deberá hacerse tanto para el otorgamiento del beneficio ${ }^{[87]}$ como para su conservación $^{[88]}$, y (iv) los órganos de la JEP efectuarán el correspondiente análisis de conformidad con los criterios de proporcionalidad ${ }^{[89]}$, razonabilidad $^{[90]}$ y gradualidad $^{[91]}$.

En este contexto, y teniendo presente que la JR constituye un principio transversal de la JEP ${ }^{[92]}$, la Sección de Apelación del Tribunal para la Paz ${ }^{[93]}$, la Sala de Definición de Situaciones Jurídicas ${ }^{[94]}$ y la Sala de Reconocimiento de Verdad, de Responsabilidad y de Determinación de los Hechos y Conductas ${ }^{[95]}$ han resaltado no sólo que el régimen de condicionalidad debe estar irradiado por la JR, sino que también aquel constituye el presupuesto necesario para su materialización. Lo anterior, por cuanto "la efectividad de la 
justicia restaurativa no puede en ningún momento alcanzarse si se mantiene la oscuridad sobre las conductas criminales y las personas afectadas" ${ }^{\prime[96]}$.

\section{La JR en el sistema de sanciones propias}

El principio de JR también se implementará en el sistema de sanciones que serán impuestas por la JEP. Así pues, en el modelo de JT colombiano se establece que las sanciones tendrán como finalidad la satisfacción de los derechos de las víctimas y materializarán una función restaurativa y reparadora del daño "siempre en relación con el grado de reconocimiento de verdad y responsabilidad" que sea efectuado por los comparecientes $^{[97]}$.

A la luz de esta disposición, se ha concebido un sistema de sanciones propias que involucra directamente a los comparecientes que reconozcan responsabilidad y verdad exhaustiva, en la reparación y restauración del daño de las víctimas ${ }^{[98]}$. Debido a la importancia de este sistema, se hará referencia a (i) su contenido; (ii) el proceso que debe surtirse para su definición y (iii) el mecanismo de supervisión y monitoreo que deberá ponerse en marcha para garantizar su cumplimiento.

En primer lugar, las sanciones propias comprenden trabajos, obras y actividades efectuadas en zonas rurales o urbanas, tales como la participación en programas de reparación para los campesinos desplazados, protección del medio ambiente, construcción y reparación de infraestructura, sustitución de cultivos de uso ilícito, desarrollo urbano, acceso a agua potable, alfabetización y erradicación de restos explosivos de guerra, entre otras ${ }^{[99]}$.

En segundo lugar, la definición de las sanciones propias responde a un complejo proceso, que parte de la formulación de un proyecto de sanciones por parte del compareciente o de la Sala de Reconocimiento de Verdad y Responsabilidad. Este documento, además de contar con un listado de actividades a desarrollar y de definir las circunstancias de tiempo, modo y lugar en las que podrían ser ejecutadas, deberá proponer un mecanismo de consulta "con los representantes de las victimas residentes en el lugar de ejecución o con las autoridades indígenas", en los casos en que así proceda, para contar con su opinión ${ }^{[100]}$. 

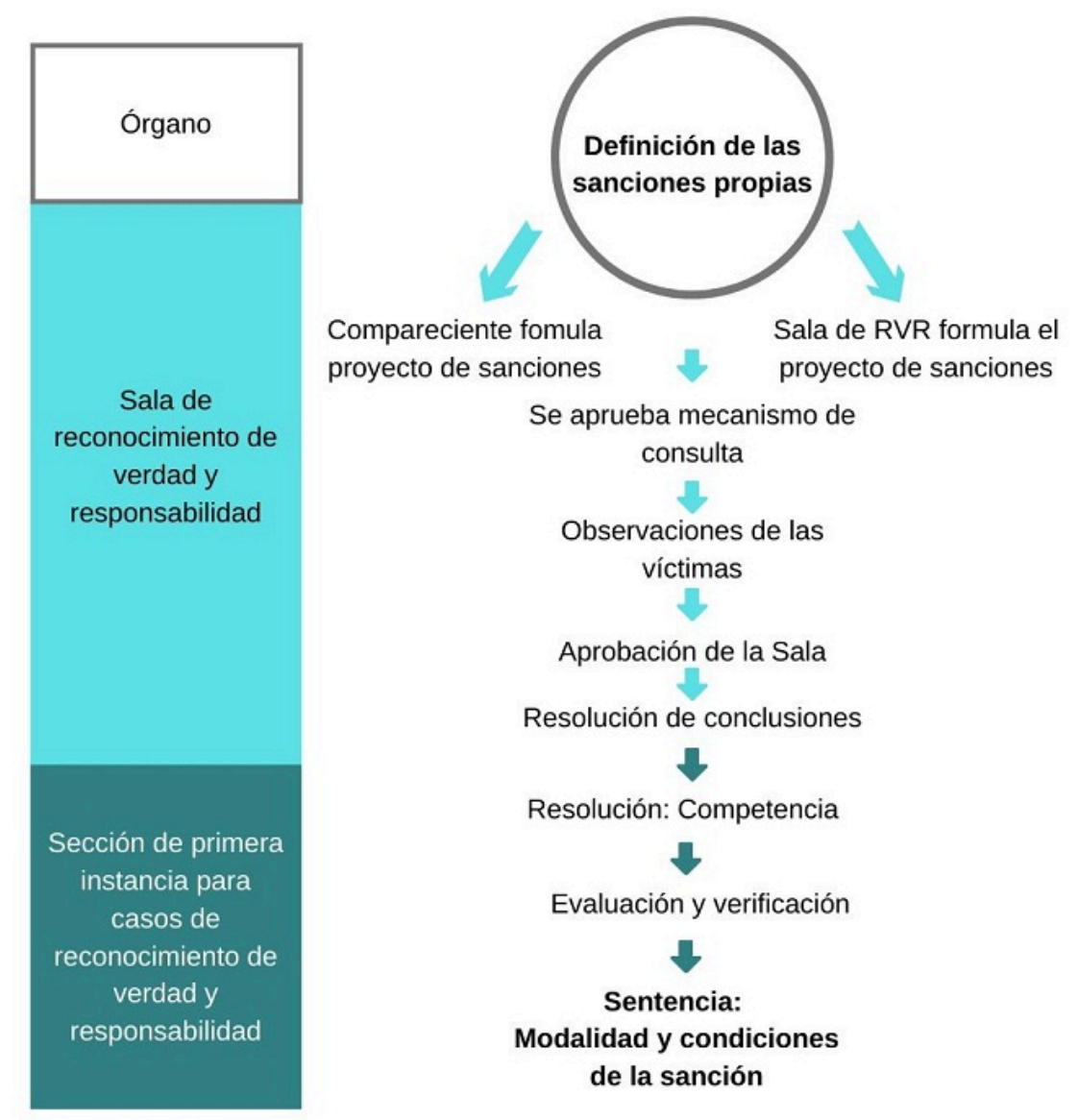

FIGURA 2.

Proceso de la sanción propia

Fuente: elaboración propia

A la Sala le corresponderá aprobarlo ${ }^{[101]}$, garantizar su contenido restaurativo y una reparación con enfoque diferencial ${ }^{[102]}$, e incluirlo en la resolución de conclusiones que es remitida a la Sección de primera instancia para casos de reconocimiento de verdad y responsabilidad ${ }^{[103]}$. En su sede, tras una evaluación de correspondencia entre el reconocimiento aportado por el compareciente y la información recolectada ${ }^{[104]}$ y un proceso de verificación del sistema de condicionalidad ${ }^{[105]}$, se procederá a proferir una sentencia que deberá detallar las sanciones impuestas y la modalidad de su cumplimiento.

Por último, la Corte Constitucional ha señalado que, en aras de armonizar la JR con la retributiva -esto es, la limitación de derechos y libertades del compareciente-, deberá garantizarse que la imposición de sanciones propias esté acompañada de un estricto sistema de monitoreo y verificación, coordinado por la JEP y las Naciones Unidas ${ }^{[106]}$.

\section{Alcance y finalidad de la reparación integral en el modelo de justicia transicional}

La reparación ha sido reconocida en diversas fuentes del modelo de JT en Colombia como un derecho de las víctimas individuales y colectivas del conflicto armado interno y también como una obligación del Estado ${ }^{[107]}$. Se orienta a remediar el daño causado, devolver a la víctima al estado en el que se encontraba con anterioridad al hecho que originó tal condición, promover un escenario de reconciliación y garantizar la no repetición de las conductas ${ }^{[108]}$. 
Este derecho de las víctimas y deber del Estado debe ser materializado, de conformidad con el marco jurídico interno, de manera integral ${ }^{[109]}$, adecuada, efectiva ${ }^{[110]}$, con enfoque diferenciado y con vocación transformadora ${ }^{[111]}$, priorizando la distribución de las medidas de reparación entre las víctimas en condiciones de igualdad y equidad ${ }^{[112]}$.

La integralidad del sistema de reparación en Colombia depende de la implementación de medidas de indemnización, restitución, satisfacción, rehabilitación, y garantías de no repetición "en sus dimensiones individual, colectiva, material, moral y simbólica" ${ }^{\text {[113]. }}$.

Al interior del SIVJRNR, se ha concebido la reparación integral a las víctimas a través de la vía administrativa -en el marco de la aplicación de la ley 1448 de 2011- ${ }^{[14]}$; la implementación del principio de condicionalidad -en tanto la contribución a la reparación constituye un requisito para el acceso a los beneficios del SIVJRNR ${ }^{[115]}$; y, por supuesto, el componente restaurativo ${ }^{[16]}$, en los procesos mismos surtidos ante la JEP y en la imposición de sanciones propias.

\section{Mecanismos actuales orientados a remediar el daño de las víctimas del conflicto armado: una relación problemática entre la JR y la reparación integral}

En la aproximación conceptual de la JR y la reparación integral se identificaron puntos en común que reflejan una necesaria relación de complementariedad entre estos dos campos. Ahora bien, estas convergencias no sólo se presentan en la teoría, sino también en la práctica. Aunque esto resulta en principio favorable \#por cuanto desde diferentes perspectivas se busca reivindicar a las víctimas y aportar a la reconciliación\#, resulta problemático, como ocurre en Colombia, que se conciba la creación de múltiples mecanismos que persiguen una misma finalidad sin que se defina normativamente la articulación que existirá entre ellos. Por lo tanto, se presentará una panorámica de las vías creadas para reparar a las víctimas y restaurar el daño.

Como se ha venido advirtiendo, el SIVJRN, y en particular, la JEP, no constituye la única vía mediante la cual se persigue la reparación y restauración del daño causado a las víctimas en el marco del conflicto armado interno. Como se observa en la Figura 3, existen al menos cinco mecanismos, identificados en diferentes jurisdicciones, que coadyuvan a la garantía del derecho a la reparación de las víctimas. 


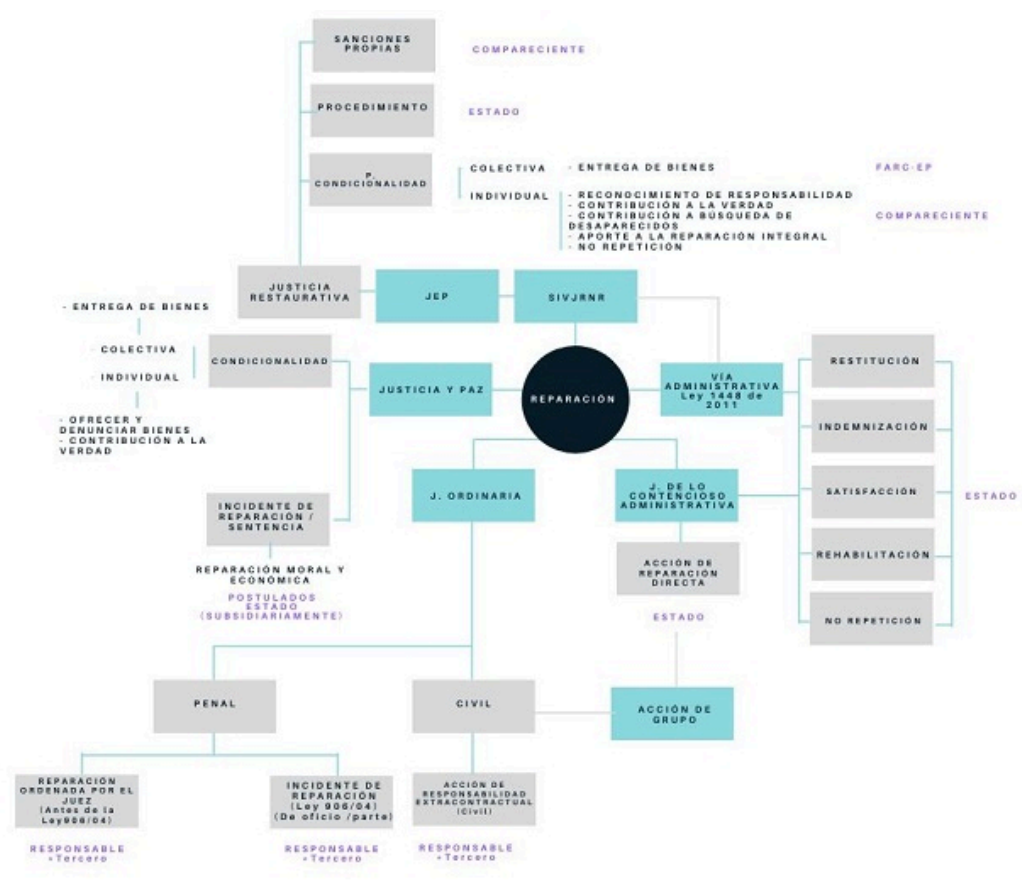

FIGURA 3.

Vías concurrentes de reparación a víctimas del conflicto armado Fuente: elaboración propia

En primer lugar, en el marco del funcionamiento de la JEP, como ya se indicó, se prevé la reparación a las víctimas a través de la materialización de la JR en tres escenarios: (i durante el proceso mismo; (ii en la aplicación del régimen de condicionalidad y (iii en el establecimiento de las sanciones con enfoque restaurativo. Lo anterior quiere decir que, como lo ha mencionado la Corte Constitucional, se concibe un régimen mixto en el que la satisfacción de cada uno de los componentes de la reparación integral recae tanto en el compareciente como en el Estado.

Así pues, el compareciente tendrá el deber de aportar (i) al componente de satisfacción, en el marco de las sanciones propias ${ }^{[117]}$ y del régimen de condicionalidad -con su contribución a la verdad ante la JEP, la Comisión de la Verdad ${ }^{[118]}$ y la Comisión de Búsqueda de Desaparecidos y a la Reparación ${ }^{[119]}$; ii) a la restitución, mediante la entrega de los bienes objeto de tal actuación ${ }^{[120]}$; iii) a la no repetición a través del compromiso presentado ante la $\mathrm{JEP}^{[121]} \mathrm{y}$ (iv a la indemnización, en los casos de terceros y civiles, que se sometan voluntariamente ante la $\mathrm{JEP}^{[122]} \mathrm{y}$, en el caso de integrantes de las FARC, a través de la entrega colectiva de los bienes para la reparación, de acuerdo con un inventario establecido ${ }^{[123]}$.

El Estado, por su parte, se encargará de la reparación en dos escenarios. Por un lado, mediante el Programa Administrativo de Reparaciones que tendrá el mandato de garantizar la rehabilitación de las víctimas -atención médica y psicosocial- y la indemnización de quienes vieron menoscabados sus derechos por la actuación de combatientes. A su vez, coadyuvará a la materialización de los otros tres elementos de la reparación integral ya señalados -restitución, satisfacción y no repetición- ${ }^{[124]}$. Por el otro lado, a través de los diferentes órganos de la JEP, se encargará de que cada etapa del procedimiento tenga una vocación reparadora ${ }^{[125]}$.

En segundo lugar, en relación con la vía administrativa, si bien ésta se encuentra contemplada como uno de los mecanismos del SIVJRNR en el Acto Legislativo 01 de 2017 y, adicionalmente, como ya se ha señalado, a través de su institucionalidad se coadyuvará a la reparación integral de las víctimas cuyos casos se encuentran sometidos a la competencia de la JEP, no puede pasarse por alto que este mecanismo se encuentra en marcha 
desde el 10 de junio de 2011 y seguirá funcionando de manera paralela a la JEP. Por lo tanto, a la fecha no sólo es posible que ya existan avances en materia de reparación integral a las víctimas de violaciones conocidas por la JEP, sino que se seguirán presentando resultados de forma concomitante ${ }^{[126]}$, siempre y cuando la Ley 1448 sea prorrogada, cuestión que, a pesar de la urgencia, aún no ha sido definida.

En tercer lugar, en el marco de Justicia y Paz -sistema transicional que surgió tras el proceso de desmovilización de los miembros de las AUC- se ha concebido la reparación a las víctimas en cuatro escenarios: (i) en el marco de los deberes adquiridos por los postulados durante el proceso -como la contribución a la verdad y a la reparación ${ }^{[127]}$; (ii) durante el incidente de reparación, en marco del cual las víctimas no sólo podrán presentar sus pretensiones, sino que podrán formularlas ante los postulados ${ }^{[128]}$; (iii) en la sentencia proferida por las Salas, en las que no sólo hay un reconocimiento de las víctimas sino una contribución a la construcción de la verdad, y (iv) en las medidas concretas de reparación ordenadas, cuyo cumplimiento se encuentra en cabeza tanto de los responsables individuales como de entidades del Estado ${ }^{[129]}$.

Aunque como lo ha reconocido la Corte Suprema de Justicia, la JEP y Justicia y Paz operan bajo sistemas completamente diferentes ${ }^{[130]}$, solo que en el marco de la reparación existen puntos de convergencia por cuanto las víctimas de los sistemas pueden coincidir en dos escenarios. Lo anterior, debido a que, por un lado, existe competencia concurrente, respecto de miembros de las FARC ${ }^{[131]}$ y, por el otro lado, a través de sus sentencias se ha coadyuvado a la construcción de la verdad, no sólo de las actuaciones de los paramilitares, sino también de Agentes del Estado y terceros. Por lo que la aplicación de la JR y la garantía de la reparación de la JEP también deberá partir de los elementos definidos en aquellas.

En cuarto lugar, resulta necesario hacer referencia a la Jurisdicción de lo Contencioso Administrativa (JCA) que, entre otras funciones, tiene como mandato la determinación de la responsabilidad del Estado por la generación de un daño antijurídico atribuible a éste ${ }^{[132]}$. En ejercicio de esta tarea, el Consejo de Estado ha liderado la consolidación de una jurisprudencia que, en aplicación de estándares internacionales, desarrolla el concepto de la reparación integral ${ }^{[133]}$, aunque aún la materialización de este concepto no sea uniforme en todas las instancias y siga siendo problemática en muchos aspectos.

Ahora bien, a pesar de que la JEP y la Jurisdicción de lo Contencioso Administrativa tienen un campo de acción diferente -determinación de la responsabilidad individual vs. institucional ${ }^{[134]}$ - existe un punto de convergencia entre ellas, en tanto la JCA ha sido esencial en el conocimiento de conductas ocurridas en el marco del conflicto armado que, por acción u omisión, han generado la responsabilidad del Estado ${ }^{[135]}$. De hecho, asuntos sobre los que la JEP ya ha avocado conocimiento, han sido abordados previamente por esta jurisdicción $^{[136]}$. Por lo tanto, algunas de las víctimas que se han acreditado como intervinientes especiales ante la SRVR, han sido beneficiarias de la reparación ordenada por sus órganos; de ahí que se plantee una posible articulación entre jurisdicciones, especialmente en los componentes de rehabilitación, restitución y satisfacción de la reparación.

Por último, la jurisdicción ordinaria interviene en dos espacios en la reparación de las víctimas del conflicto armado interno: (i) procesos penales culminados, en los que ya se haya condenado al responsable y, en el marco del incidente de reparación integral -tras la Ley 906 de 2004- se hayan ordenado medidas de reparación en cabeza del victimario, o estas medidas de reparación hayan sido ordenadas de oficio por los jueces penales, y (ii) resolución de la solicitud de indemnización de las víctimas por actos sometidos a la competencia de la JEP que no hayan sido cometidos por combatientes ${ }^{[137]}$.

Por último, en el marco de la jurisdicción ordinaria y de lo contencioso administrativa se encuentra la acción de grupo, que es interpuesta por un número plural o un conjunto de personas que comparten las condiciones y causas que originaron los perjuicios individuales sufridos por aquellas. Esta acción, definida en el título 3 de la ley 472 de 1998, también ha sido invocada por víctimas del conflicto armado, persiguiendo la reparación, bien sea en cabeza del Estado ${ }^{[138]}$ o del sujeto responsable ${ }^{[139]}$, según corresponda. 
Estas vías, como se evidencia, a pesar de que tienen un alcance y objeto específico, al contener puntos de convergencia e interconexión, requieren de un marco articulador que, de manera efectiva y eficiente, permita la satisfacción de los derechos de las víctimas.

\section{Desafíos pendientes: hacia la materialización de la JR y la construcción de una relación entre la justicia restaurativa y la reparación en Colombia}

Los desafíos desarrollados en este artículo muestran que hay un importante camino por recorrer para lograr la materialización de la justicia restaurativa, en especial en su relación con el componente de reparación en el modelo de justicia transicional en Colombia. Por supuesto, de cara al abordaje de estos desafíos, no pretendemos agotar la discusión respecto de las alternativas que pueden construirse para la solución de los principales problemas. Sin embargo, a manera de conclusión, quisiéramos presentar algunas propuestas iniciales, para contribuir a este urgente debate en Colombia.

\section{En relación con la materialización de la justicia restaurativa}

El artículo 27 de la Ley de Procedimiento de la Jurisdicción Especial para la Paz le apuesta al paradigma de la justicia restaurativa, al establecer (i) la responsabilidad de la JEP de promover la construcción dialógica de la verdad entre los sujetos procesales e intervinientes para conseguir una "armonización y sanación individual, colectiva y territorial", (ii) la necesidad de promover acuerdos en todas las fases del procedimiento, con criterios de razonabilidad y proporcionalidad, (iii) la posibilidad de tomar en cuenta las prácticas restaurativas de las justicias étnicas, y (iv) la responsabilidad de incluir en la Resolución de Conclusiones el proyecto de sanciones con contenido reparador y las medidas restaurativas, que podrán ser definidas con participación de las víctimas.

Definir cómo se va a materializar esta disposición de la Ley de Procedimiento es esencial, para lo cual resultaría interesante elaborar una guía orientadora para la implementación del componente restaurativo, que sea clara al explicar cómo se hará efectivo el principio en cada fase del proceso.

Se prefiere este camino a una posible reforma legislativa, por cuanto requiere no sólo de una convergencia multidisciplinaria, sino porque demanda un grado cualificado de especificidad y, también, porque la voluntad política necesaria para tramitar una ley puede resultar difícil de concretar.

En este marco resulta importante definir (i) los espacios, la metodología y las reglas de encuentro entre víctimas y victimarios y el rol que se le dará a las versiones voluntarias como espacios que pueden tener efectos restaurativos; (ii) las cuestiones que son o no susceptibles de ser acordadas entre las partes; (iii) el rol que jugarán los magistrados en cada fase; (iv) el alcance del mecanismo de consulta con las víctimas, las posibilidades de diálogo directo en este proceso, y las consecuencias que tendrán posibles objeciones de las víctimas a los proyectos de sanciones; (v) el papel que jugarán en los procesos las víctimas acreditadas en el proceso y las que no lo están; (vi) el alcance y los límites del componente restaurativo de las sanciones, (vi) el alcance, contenido y reglas de los reconocimientos de responsabilidad; y (vii) el impacto del principio de la $\mathrm{JR}$ en los procesos con ausencia de reconocimiento de responsabilidad total o parcial, o con reconocimiento tardío en la etapa de juicio oral.

En especial, respecto de los reconocimientos de responsabilidad, a pesar de que la Ley de Procedimiento permite que se realicen por escrito ${ }^{[140]}$, uno de los retos más importantes será privilegiar las audiencias de reconocimiento; lograr que estas sean verdaderos espacios restaurativos, y que la atención no se enfoque únicamente en los victimarios, sino también en las víctimas. Para lograr estos objetivos, la preparación por parte de la JEP a los intervinientes y las claridades metodológicas y de moderación de las expectativas serán 
esenciales para que estos escenarios no se conviertan en espacios de revictimización. Igualmente, se debe entender que en estos encuentros los protagonistas son las partes, víctima y victimario, por tanto, quien acompañe el encuentro deberá actuar como un facilitador y no como un juez ${ }^{[141]}$. Por último, se deberá asegurar que la participación de las partes sea voluntaria ${ }^{[142]}$, sin que esto impida que, para el caso del victimario, pueda ejecutarse una sanción efectiva ${ }^{[143]}$.

La definición de reglas precisas resulta realmente importante si se tiene en cuenta que las expectativas para todos los actores del proceso deben estar claras ${ }^{[144]}$, así como los derechos que tienen las partes respecto de posibles encuentros con enfoque restaurativo ${ }^{[145]}$. Por ejemplo, existen claros estándares internacionales respecto de los derechos de las víctimas de ciertas violaciones, como la violencia sexual, a no tenerse que encontrar con sus agresores ${ }^{[146]}$.

\section{En relación con la articulación de los mecanismos}

Un mensaje central y transversal es que uno de los desafíos principales está en la coordinación y coherencia, no solo entre los mecanismos judiciales y extrajudiciales que componen el modelo de justicia transicional en Colombia; sino también entre estos mecanismos y aquellos que siguen operando ordinariamente en el país. Asimismo, en la construcción de propuestas, la visión sobre la integralidad pasa también por considerar que el SIVJRNR fue construido en diálogo e interacción con los demás puntos del Acuerdo Final de Paz, por lo que un análisis aislado de la implementación del Punto de Víctimas del Acuerdo, sin tener en cuenta su relación con los otros, no sólo resulta insuficiente ${ }^{[147]}$, sino que genera un desgaste institucional grave, teniendo en cuenta la limitación de recursos estatales propia de los escenarios de transición, al tener que enfrentarse a la multiplicidad de víctimas y hechos victimizantes tras un escenario de masivas vulneraciones a los derechos humanos.

Por ello, la primera y más importante recomendación consiste en la necesidad de promover una articulación en diferentes niveles; no sólo los mecanismos que componen el SIVJRNR, sino todas las diferentes vías que persiguen las mismas finalidades del SIVJRNR y tienen un mismo campo de acción.

Así pues, en primer lugar, resulta fundamental que se articule el régimen de condicionalidad con el sistema de sanciones en la JEP. En segundo lugar, debe garantizarse una integración real entre la JEP, la CEV y a la $\mathrm{CBD}$. En tercer lugar, debe promoverse un trabajo mancomunado entre tales órganos del SIVJRN y otros mecanismos, tanto de naturaleza transicional, como aquellos que sin tenerla coadyuvan a la reparación de víctimas del conflicto armado como: los mecanismos derivados de la Ley 1448 de 2011 y especialmente el SNARIV; la Unidad de Justicia y Paz; a los mecanismos derivados de la justicia ordinaria y a los mecanismos derivados de las jurisdicciones constitucionales y administrativas. Tampoco se puede perder de vista a Agencias como la de Reincorporación (ARN) y a las entidades territoriales, en donde resulta pertinente.

Las herramientas para algunas propuestas de articulación ya se encuentran contempladas en la ley, y solo requieren una acción específica por parte de algún mecanismo. Por ejemplo, en uso la facultad consagrada en el artículo 114.14 de la Ley Estatutaria ${ }^{[148]}$, la Secretaría de la JEP podría solicitar conceptos e información a los órganos que hayan avanzado en otorgar medidas de reparación a las víctimas, con el fin de que sean remitidos a la Sala de Reconocimiento de Verdad y Responsabilidad para que sean tenidas en cuenta en la formulación del proyecto de sanciones con contenido restaurativo, o para establecer los avances en el cumplimiento de los requisitos del régimen de condicionalidad. Las medidas adelantadas en el marco del cumplimiento de las condiciones, por supuesto, deberán ser además punto de partida de sanciones con efectos restaurativos. Asimismo, la creación de mesas técnicas interinstitucionales de coordinación o grupos de trabajo al interior de las entidades encargadas de materializar la coordinación ${ }^{[149]}$ requiere únicamente que exista voluntad política de las partes involucradas y mecanismos robustos de seguimiento a los compromisos ${ }^{[150]}$. 
En cambio, otras acciones de articulación pueden requerir cambios mucho más esenciales que pueden implicar modificaciones legales e incluso constitucionales. Un debate abierto y pendiente, por ejemplo, es si deben establecerse límites a la jurisdicción contenciosa administrativa para ordenar reparaciones, cuando los hechos sometidos a su conocimiento coincidan con aquellos que son a su vez de competencia de la Jurisdicción Especial para la Paz. Tal como está concebido el SIVJRNR, las reparaciones a las víctimas del conflicto armado deberían estar concentradas en el programa administrativo de reparaciones \#en articulación con los aportes que en este aspecto pueden tener las medidas con carácter restaurativo que han sido desarrolladas en este artículo\#, y este parámetro resulta problemático si la jurisdicción administrativa retiene su competencia plena para decretar reparaciones con estándares judiciales, con un enfoque por completo individual, y sin tener en cuenta el enfoque restaurativo del modelo de justicia transicional.

Aunque este debate es difícil, no puede ser aplazado por mucho tiempo, en especial si se tiene en cuenta que el Consejo de Estado ha considerado que su relación con la JEP resulta relevante para hacer efectivo, a través de sus órdenes, el deber de investigar, juzgar y sancionar. Sin embargo, también considera que la existencia del SIVJRNR no altera en absoluto su competencia para ordenar indemnizaciones, aunque sí se avizore una voluntad de coordinación frente a otras medidas de reparación, como las de satisfacción ${ }^{[151]}$ e, incluso, garantías de no repetición ${ }^{[152]}$. Concretar estas relaciones de colaboración y definir los límites a las órdenes de indemnización, requerirá modificaciones normativas, al menos en algunos aspectos.

\section{Relación de la justicia restaurativa y la reincorporación}

Aunque el principio de centralidad de los derechos de las víctimas no puede perderse de vista, el rol de los victimarios en la justicia restaurativa también resulta esencial, tal como lo hemos planteado. De hecho, las teorías acerca de lo problemático que resulta pensar en una dualidad radical víctima/victimario, son cada vez más comunes y necesarias en la literatura sobre contextos de graves violaciones a los derechos humanos ${ }^{[153]}$.

Por tanto, reflexionar y repensar la forma de articular la justicia restaurativa, la reparación integral y el proceso de reincorporación, es un debate difícil, pero urgente en Colombia. Especialmente, por cuanto, a través de la línea de reintegración comunitaria, desarrollada por la Agencia Nacional para la Reincorporación con apoyo de la Organización Internacional para las Migraciones ${ }^{[154]}$, se ha promovido la reincorporación del victimario, mediante la implementación de medidas que, en la práctica, tienen un componente restaurativo en tanto garantizan la reparación de víctimas y de las comunidades y promueven un escenario de reconciliación y una reconstrucción del tejido social.

Como materialización de tal proceso de reintegración comunitaria, se identifican aquellas iniciativas que a través del (i) teatro ${ }^{[155]}$; (ii) la música ${ }^{[156]}$; (iii) la cultura autóctona ${ }^{[157]}$; (iv) la danza ${ }^{[158]}$ y (v) el arte ${ }^{[159]}$, no sólo crean espacios de interlocución y diálogo entre las partes, sino que se asignan tareas compartidas que requieren de un trabajo en equipo y de una consolidación de confianza mutua, entre víctimas, victimarios y comunidades, que cultivan un escenario de reconciliación.

\section{A modo de conclusión}

Teniendo presente que (i) la JR no es un concepto propio de la JT y que su materialización en contextos de transición requiere de una articulación con la justicia retributiva y (ii) si bien la JR y la reparación tienen un origen y contenido diferente, sí existe una clara convergencia en los fines perseguidos \#generando una cualificación de doble vía\#, Colombia se enfrenta a importantes retos relacionados no sólo con la garantía de un efecto útil a la justicia restaurativa en su modelo de JT, sino a la articulación con los demás componentes del SIVJRNR. 
El desarrollo efectuado en el presente artículo, más que respuestas, plantea relevantes cuestionamientos y desafíos de cara al proceso de implementación del principio de JR en el modelo de justicia transicional en Colombia. Las reflexiones constituyen un punto de partida para el abordaje de complejos debates que requieren una atención inmediata, no sólo para dotar de efectos reales el principio de JR en el modelo de JT colombiano, sino también integrar los diferentes mecanismos creados en el nivel interno para cumplir con el propósito de reparar a las víctimas, y para promover un verdadero escenario de reconciliación.

Sin lugar a dudas, el ordenamiento jurídico colombiano tiene la potencialidad para alcanzar los fines últimos del proceso de construcción de paz. La tarea, entonces, consiste en definir el camino, el método y la metodología para que las normas proferidas no se queden en meras aspiraciones, sino que realmente tenga una materialización armónica y efectiva.

\section{Bibliografía}

Acto Legislativo 01 de 2017 [Congreso de Colombia]. Por medio del cual se crea un título de disposiciones transitorias de la constitución de una paz estable y duradera y se dictan otras disposiciones. 4 de abril de 2017.

Acuerdo Final de Paz [Gobierno Nacional y FARC-EP]. Acuerdo final para la terminación del conflicto y la construcción de una paz estable y duradera. 12 de noviembre de 2016. https://www.cancilleria.gov.co/sites/def ault/files/Fotos2016/12.11_1.2016nuevoacuerdofinal.pdf

Alejandro Gómez \& Julián Correa, ¿Sobredimensión de la tensión entre justicia y paz? Reflexiones sobre justicia transicional, justicia penal y justicia restaurativa en Colombia, 13 International Law: Revista Colombiana de Derecho Internacional, n. ${ }^{\circ} 26,192-248$ (2015). https://doi.org/10.11144/Javeriana.il15-26.stjp

Allison Morris, Critiquing the critics: a brief response to critics of restorative justice, 42 British Journal of Criminology, n. ${ }^{\circ}$ 3, 596-615 (2012). https://doi.org/10.1093/bjc/42.3.596

Allison Morris \& Gabrielle Maxwell, Restorative Justice in New Zealand: Family Group Conferences as a Case Study, 1 Western Criminology Review, n. ${ }^{\circ} 1$ (1998). http://www.westerncriminology.org/documents/WCR/v01n1/ Morris/Morris.html

Andrew Ashworth, Is Restorative Justice the Way Forward for Criminal Justice? 54 Current legal problems, n. ${ }^{\circ}$ 1, 347-376 (2001). https://doi.org/10.1093/clp/54.1.347

Andrew Ashworth, Responsibilities, Rights and Restorative Justice, 42 The British Journal of Criminology, n. ${ }^{\circ}$ 3, 578-595 (2002). https://doi.org/10.1093/bjc/42.3.578

Andrew Bottoms, Some sociological reflections on restorative justice, en Restorative juvenile justice and criminal justice: Competing or reconcilable paradigms? 79-114 (von Hirsch A., Roberts J., Bottoms A., Roach K. \& Schiff M., eds., Criminal Justice Press, 2003). 10.5040/9781472559333.ch-005

Anna Eriksson, A Bottom-Up approach to transformative justice in Northern Ireland, 3 International Journal of Transitional Justice, n. ${ }^{0}$ 3, 301-320 (2009). https://papers.ssrn.com/sol3/papers.cfm?abstract_id=1493557

Annie Cossins, Restorative Justice and child sex offences: The theory and practice, 48 British Journal of Criminology, 359-378 (2008). https://papers.ssrn.com/sol3/papers.cfm?abstract_id $=1398603$

ARN. A través de obra de teatro, la ARN construye reconciliación en Cundinamarca. (20 de noviembre, 2017). http://www.reincorporacion.gov.co/es/sala-de-prensa/noticias/Paginas/2017/11/obra-de-teatro-ARN -construye-reconciliacion-Cundinamarca.aspx

ARN. "Con disciplina se materializan los sueños": Diego Saldarriaga. $(15$ de septiembre, 2017). http://www.reincorporacion.gov.co/es/sala-de-prensa/noticias/Paginas/2017/09/Con-disciplina-se-m aterializan-los-suenios-Diego-Saldarriaga.aspx

ARN. La danza árabe como herramienta de reconciliación y liderazgo de la mujer. (7 de abril, 2017). http://www.reinc orporacion.gov.co/es/sala-de-prensa/noticias/Paginas/2017/04/danza-arabe-herramienta-reconciliacion.aspx 
ARN. Noche de música, baile y narrativas, al cierre de iniciativa de jóvenes en reintegración en Bucaramanga. (1 de diciembre, 2017). http://www.reincorporacion.gov.co/es/sala-de-prensa/noticias/Paginas/2017/12/iniciativajovenes-reintegracion-Bucaramanga.aspx

ARN. Obra de teatro de personas desmovilizadas y niños con discapacidad cognitiva estará en la clausura de las Olimpiadas FIDES. (12 de junio, 2015). http://www.reincorporacion.gov.co/es/sala-de-prensa/noticias/Paginas/2015/06 /12.aspx

ARN. Reconciliémonos a través del arte. (8 de noviembre, 2017). http://www.reincorporacion.gov.co/es/sala-de-pren sa/noticias/Paginas/2017/11/Reconciliemonos-a-traves-del-arte.aspx

ARN. Tejiendo sueños a través de la música. (30 de junio, 2016)http://www.reincorporacion.gov.co/es/sala-de-prens a/noticias/Paginas/30062016-C.aspx

Caso Colindres Schonenberg vs. El Salvador, Fondo, Reparaciones y Costas, Corte I.D.H. (4 de febrero de 2019).

Caso de las Comunidades Afrodescendientes desplazadas de la Cuenca del Río Cacarica (Operación Génesis) vs. Colombia, Excepciones Preliminares, Fondo, Reparaciones y Costas, Corte I.D.H. (20 de noviembre de 2013).

Caso Gelman vs. Uruguay. Fondo y Reparaciones, Corte I.D.H. (24 de febrero de 2011).

Caso Masacres de El Mozote y lugares aledaños vs. El Salvador. Fondo, Reparaciones y Costas, Corte I.D.H. (25 de octubre de 2012).

Caso Órdenes Guerra y otros vs. Chile, Fondo, Reparaciones y Costas, Corte I.D.H. (29 de noviembre de 2018).

Caso Rosendo Cantú y Otra vs. México, Excepción Preliminar, Fondo, Reparaciones y Costas, Corte I.D.H. (15 de mayo de 2010).

Caso Villaseñor Velarde y otros vs. Guatemala, Fondo, Reparaciones y Costas, Corte I.D.H. (5 de febrero de 2019).

Caso Yarce y otras vs. Colombia, Excepción Preliminar, Fondo, Reparaciones y Costas, Corte I.D.H. (22 de noviembre de 2016).

CIDH, Verdad, justicia y reparación: cuarto informe sobre la situación de derechos humanos en Colombia, OEA/ Ser.L/V/II, Doc. 49/13 (2013). https://www.oas.org/es/cidh/docs/pdfs/Justicia-Verdad-Reparacion-es.pdf

Collen Murphy, Judging the Justice of the Colombian Final Agreement, 1-13 (Working Paper, 2019).

Comisión de Derechos Humanos, Conjunto de principios actualizado para la protección y la promoción de los derechos humanos mediante la lucha contra la impunidad, E/CN.4/2005/102/Add.1 (2005). http://www.der echos.org/nizkor/impu/impuppos.html

Consejo de Derechos Humanos, Informe del Relator Especial sobre la promoción de la verdad, la justicia, la reparación y garantías de no repetición, Pablo de Greiff, A/HRC/21/46 (2012). https://www.ohchr.org/Documents/HR Bodies/HRCouncil/RegularSession/Session21/A-HRC-21-46_sp.pdf

Consejo de Estado, Intervención ante el Congreso de la República sobre la Jurisdicción Especial para la Paz (2016). h ttp://consejodeestado.gov.co/documentos/publicaciones/IntervencJEPCongreso.pdf.

Consejo de Estado, Sala de lo Contencioso Administrativo, Sala Plena, Sección Tercera. Sentencia 1999-01063/32988 de 2014 (C. P. Ramiro de Jesús Pazos Guerrero; 28 de agosto de 2014). 32.888.

Consejo de Estado, Sala de lo Contencioso Administrativo, Sección primera Sentencia 29 de abril de 2010, 37.501.

Consejo de Estado, Sala de lo Contencioso Administrativo, Sección tercera, Sentencia 54001-23-31-000-1996-09890-01(21660), 29 de febrero de 2012, 21.660).

Consejo de Estado, Sala de lo Contencioso Administrativo, Sección tercera, Subsección B, Sentencia 2000-03838, 22 de abril de 2015, 19.146.

Consejo de Estado, Sala de lo Contencioso Administrativo, Sección tercera, subsección B, Sentencia 2011-00096, 30 de noviembre de 2017, 46.567.

Consejo de Estado, Sala de lo Contencioso Administrativo. Sección tercera - Subsección B. 10 de mayo de 2018. 15001-23-31-000-2007-00694-01.

Consejo de Estado, Sala de lo Contencioso Administrativo, sección tercera, subsección B, 14 de febrero de 2018, 525616. 
Consejo de Estado, Sala de lo Contencioso Administrativo, Sección tercera, subsección C, Sentencia 85001-23-31-000-2010-00178-01 (47671), 7 de septiembre de 2015, 47.671.

Consejo de Estado, Sala de lo Contencioso Administrativo, Sección tercera, 15 de agosto de 2018, 46.947.

Consejo de Estado, Sala de lo Contencioso Administrativo. 15 de agosto de 2007. 190012331000200300385-01.

Consejo de Estado, Sala Plena de lo Contencioso Administrativo, 13 de marzo del 2018, 28.769.

Consejo Económico y Social de las Naciones Unidas, E/CN.15/2002/5/Add.1, Justicia restaurativa, Informe del Secretario General (2002).

Convención do Belém do Pará, Organización de estados americanos (1994).

Corte Constitucional. Sentencia C-080 de 2018 (M. P. Antonio José Lizarazo Ocampo; 15 de agosto de 2018).

Corte Constitucional de Colombia. Sentencia C-007 de 2018 (M. P. Diana Fajardo Rivera; 1 de marzo de 2018).

Corte Constitucional de Colombia. Sentencia C-055 de 2010 (M. P. Juan Carlos Henao Pérez; 3 de febrero de 2010).

Corte Constitucional de Colombia. Sentencia C-180 de 2014 (M. P. Alberto Rojas Ríos; 27 de marzo de 2014).

Corte Constitucional de Colombia. Sentencia C-233 de 2016 (M. P. Luis Ernesto Vargas Silva; 11 de mayo de 2016).

Corte Constitucional de Colombia. Sentencia C-253A de 2012 (M. P. Gabriel Eduardo Mendoza Martelo; 29 de marzo de 2012).

Corte Constitucional de Colombia. Sentencia C-280 de 2013 (M. P. Nilson Pinilla Pinilla; 15 de mayo de 2013).

Corte Constitucional de Colombia. Sentencia C-286 de 2014 (M. P. Luis Ernesto Vargas Silva; 20 de mayo de 2014).

Corte Constitucional de Colombia. Sentencia C-370 de 2006 (M. Ps. Manuel José Cepeda Espinosa, Jaime Córdoba Triviño, Rodrigo Escobar Gil, Marco Gerardo Monroy Cabra, Álvaro Tafur Galvis, Clara Inés Vargas Hernández; 18 de mayo de 2016).

Corte Constitucional de Colombia. Sentencia C-579 de 2013 (M. P. Jorge Ignacio Pretelt Chaljub; 28 de agosto de 2013).

Corte Constitucional de Colombia. Sentencia C-674 de 2017 (M. P. Luis Guillermo Guerrero Pérez; 14 de noviembre de 2017).

Corte Constitucional de Colombia. Sentencia C-694 de 2015 (M. P. Alberto Rojas Ríos; 11 de noviembre de 2015).

Corte Constitucional de Colombia. Sentencia C-715 de 2012 (M. P. Luis Ernesto Vargas Silva; 13 de septiembre de 2012).

Corte Constitucional de Colombia. Sentencia C-795 de 2014 (M. P. Jorge Iván Palacio Palacio; 30 de octubre de 2014).

Corte Constitucional de Colombia. Sentencia C-820 de 2012 (M. P. Mauricio González Cuervo; 18 de octubre de 2012).

Corte Constitucional de Colombia. Sentencia C-979 de 2005 (M. P. Jaime Córdoba Triviño; 26 de septiembre de 2005).

Corte Constitucional de Colombia. Sentencia SU-254 de 2013 (M. P. Luis Ernesto Vargas Silva; 24 de abril de 2013).

Corte Constitucional de Colombia. Sentencia T-037 de 2015 (M. P. Jorge Ignacio Pretelt Chaljub; 28 de enero de 2015).

Corte Constitucional de Colombia. Sentencia T-130 de 2016 (M. P. Jorge Ignacio Pretelt Chaljub; 14 de marzo de 2016).

Corte Constitucional de Colombia. Sentencia T-174 de 2016 (M. P. Alberto Rojas Ríos; 11 de abril de 2016).

Corte Constitucional de Colombia. Sentencia T-197 de 2015 (M. P. Martha Victoria Sáchica Méndez; 20 de abril de 2015).

Corte Constitucional de Colombia. Sentencia T-234 de 2012 (M. P. Gabriel Eduardo Mendoza Martelo; 21 de marzo de 2012).

Corte Constitucional de Colombia. Sentencias T-083 de 2017 (M. P. Alejandro Linares Cantillo; 13 de febrero de 2017).

Corte Suprema de Justicia, Auto interlocutorio (M. P. Gustavo Enrique Malo Fernández; 16 de marzo de 2007) 
Corte Suprema de Justicia. Sala de Casación Penal. Proceso No. 19044 (M. P. Edgar Lombana Trujillo; 12 de noviembre de 2003).

David Dyzenhaus, Judicial Independence, Transitional Justice and the Rule of Law, 10 Otago Law Review, n. ${ }^{\circ}$ 4, 345-370 (2003). http://www8.austlii.edu.au/nz/journals/OtaLawRw/2003/4.html

David Dyzenhaus \& Alma Diamond, The Resilient Constitution, 1-19 (Corte Constitucional de Colombia, Working Paper, 2019).

Declan Roche, Restorative Justice and the Regulatory State in South African Townships, 42 British Journal of Criminology, n. ${ }^{\circ} 3$, 514-533 (2002). https://doi.org/10.1093/bjc/42.3.514

Diana Brito Ruiz, Justicia Restaurativa: Reflexiones sobre la experiencia de Colombia, 66-74 (2010).

Diane Sivasubramaniam, A special issue on restorative justice: unravelling the mystery, 20 Critical Criminology, 1-7 (2012). https://doi.org/10.1007/s10612-011-9148-6

Ezzat Fattah, Some reflections on the paradigm of restorative justice and its viability for juvenile justice, en Restorative justice for juveniles: Potentialities, risks and problems, 389-401 (Lode Walgrave, ed., Leuven University Press, 1998).

Fernández Ortega y Otros vs. México, Excepción Preliminar, Fondo, Reparaciones y Costas, Corte I.D.H. (30 de agosto de 2010).

George Mousourakis, Understanding and implementing restorative justice, 11 Tilburg Foreign Law Review, n. 3 , 626-652 (2003).

Gina Rodríguez, Los límites del perdón. Notas sobre la justicia transicional en Sudáfrica, Centroamérica y Colombia, 7 Revista Justicia Juris, n. ${ }^{\circ} 2$, 52-66 (2011). https://dialnet.unirioja.es/servlet/articulo?codigo $=4122138$

Grupo de Expertos sobre Justicia Restaurativa, Consejo Económico y Social, E/CN.15/2002/5/Add.1 (2002).

Gwen Robinson \& Joanna Shapland, Reducing Recidivism: A task for Restorative Justice? 48 British Journal of Criminology, n. ${ }^{\circ} 3$, 337-358 (2008). https://doi.org/10.1093/bjc/azn002

Heather Strang \& Laurence W. Sherman, Repairing the harm: Victims and Restorative Justice, 15 Utah Law Review, n. ॰1, 15-42 (2003). http://hdl.handle.net/1885/29887

Hennessey Hayez, Tara R. McGee, Helen Punter \& Michael J. Cerruto, Exploring the Implications of Agreements for Post-Conference Offending Behaviour, 54 British Journal of Criminology, n. ${ }^{\circ}$ 1, 109-127 (2014). https://doi.or $\mathrm{g} / 10.1093 / \mathrm{bjc} / \mathrm{azt} 056$

Henry Vásquez \& Jairo Rojas, Tratamiento de la delincuencia juvenil en Colombia en el sistema de responsabilidad de adolescentes, Verba Iuris, n. ${ }^{\circ} 30,115-133$ (2013). https://doi.org/10.18041/0121-3474/verbaiuris.30.2163

I Daniel W. Van, Restoring justice: an introduction to restorative justice, 5-256 (5.. ed., Routledge, 2014).

I Gerry Johnstone, Restorative Justice: Ideas, Values, Debates, (2.. ed., Routledge, Londres, 2013).

I Gerry Johnstone \& Daniel W. Van, Handbook of Restorative Justice (1.. ed., William Publishing, 2007).

I Howard Zehr, El pequeño libro de la Justicia Restaurativa (1.. ed., Good Books, 2010).

IFIT, Los debates de La Habana: una mirada desde adentro (1.. ed., Andrés Bermúdez, ed., 2018).

Iván Orozco, La posguerra colombiana: Divagaciones sobre la venganza, la justicia y la reconciliación, Análisis Político, n. ${ }^{\circ} 46,78-99$ (2002). https://revistas.unal.edu.co/index.php/anpol/article/view/80257

James A. Sweeney, Restorative Justice and Transitional Justice at the ECHR, 12 International Criminal Law Review, $\mathrm{n}$. ○3, 313-338 (2012). https://doi.org/10.1163/157181212X648897

Janine N. Clark, The three Rs: retributive justice, restorative justice, and reconciliation, 11 Contemporary Justice Review, n. ${ }^{\circ} 4,331-350$ (2008). https://doi.org/10.1080/10282580802482603

Jeff Latimer, Dowden Craig \& Muise Danielle, The effectiveness of restorative justice practices: A meta-analysis, 85 The prison journal, n. ${ }^{\circ} 2,127-144$ (2005). https://doi.org/10.1177/0032885505276969

Jennifer J. Llewellyn, Institutions for restorative justice: The South African truth and reconciliation commission, 49 The University of Toronto Law Journal, n. 3 3, 355-388 (1999). https://doi.org/10.2307/826003 
JEP. Sala de Definición de Situaciones Jurídicas. Resolución diciembre de 2018. Compareciente: Henry William Torres Escalante.

JEP. Sala de definición de situaciones jurídicas. Subsala séptima. Resolución 0035 de 2019. Compareciente: Willinton de Jesús Graciano Sepúlveda.

JEP. Sala de definición de situaciones jurídicas. Subsala sexta. Resolución 1941 de 2019. Compareciente: José Gregorio Hernández.

JEP. SRVR. Auto No. 060. 5 de octubre de 2018. Caso 001.

JEP. Tribunal para la Paz. Sección de apelación. Auto TP-SA 123 de 2019.

JEP. Tribunal para la Paz. Sección de Apelación. Auto TP-SA 19 de 2018, 21 de agosto de 2018. Compareciente: David Char Navas.

JEP. Tribunal para la Paz. Sección de Revisión. SRT-AR-003/2018. 24 de octubre de 2018. Jorge Eliécer Plazas Acevedo.

Johanna Shapland, Restorative justice: the views of victims and offenders, 3 Ministry of Justice Research Series, 7, (2007). http://crjc.ca/wp-content/uploads/Restorative-Justice-the-Views-of-Victims-and-Offenders.pdf

John Braithwaite, Setting Standards for Restorative Justice, 42 The British Journal of Criminology, n. ${ }^{\circ}$ 3, 563-577 (2002). https://doi.org/10.1093/bjc/42.3.563

John Braithwaite, The fundamentals of restorativejustice, en A kind of mending: Restorative Justice in the Pacific Islands, 35-43 (Sinclair Dinnen, ed., ANU Press, 2010). https://doi.org/10.22459/KM.11.2010.02

Julio A. Sampedro, La justicia restaurativa: una nueva vía desde las victimas en la solución al conflicto penal, 8 Interantional Law: Revista Colombiana de Derecho Internacional, n. ${ }^{\circ}$ 17, 87-124 (2010). https://revistas.javer iana.edu.co/index.php/internationallaw/article/view/13821

Karen G. Domínguez \& Tatiana A. Rosero, Justicia sobre la hierba. Tribunales Gacaca, lecciones de reconciliacio\#n para Colombia, Estudios Políticos, n. ${ }^{\circ}$ 51, 218-239. http://dx.doi.org/10.17533/udea.espo.n51a11

Karla Villareal, La victima, el victimario y la justicia restaurativa, 7 Rivista di Criminología, Vittimologia e Sicurezza, n. ${ }^{\circ} 1,43-57$ (2013). https://www.vittimologia.it/rivista/articolo_villarrealsotelo_2013-01.pdf

Katherine Basire, Taking Restorative Justice Seriously, 13 Canterbury Law Review, n. ${ }^{\circ}$ 1, 31-57 (2007).

Kathleen Daly, Restorative justice and sexual assault: An archival study of the Court and conference cases, 46 British Journal of Criminology, n. ${ }^{\circ} 2$, 334-356 (2005). https://doi.org/10.1093/bjc/azi071

Kathleen Daly, What is Restorative Justice? Fresh answers to a vexed question, 11 Victims \& offenders, n. ${ }^{\circ}$ 1, 9-29 (2011). https://doi.org/10.1080/15564886.2015.1107797

Kerry Clamp \& Jonathan Doak, More than Words: Restorative Justice Concepts in Transitional Justice Settings, 12 International Criminal Law Review, n. ${ }^{\circ}$ 3, 339-360 (2012). https://doi.org/doi:10.1163/157181212X648824

Kieran McEvoy \& Harry Mika, Punishment, policing and praxis: Restorative justice and non\#violent alternatives to paramilitary punishments in Northern Ireland, 11 Policing and Society: An International Journal, n. ${ }^{\circ}$ 3-4, 359-382 (2011). https://doi.org/10.1080/10439463.2001.9964871

Kieran McEvoy \& Harry Mika, Restorative Justice and the Critique, British Journal of Criminology, n. ${ }^{\circ} 42$, 534-562 (2002). https://doi.org/10.1093/bjc/42.3.534

Kieran McEvoy, Harry Mika \& Barbara Hudon, Introduction: Practice, Performance and Prospects for Restorative Justice, 42 The British Journal of Criminology, n. ${ }^{\circ} 3$, $469-475$ (2002). https://www.jstor.org/stable/23638876

Laurel E. Fletcher \& Harvey M. Weinstein, Writing Transitional Justice: An Empirical Evaluation of Transitional Justice Scholarship in Academic Journals, 7 Journal of Human Rights Practice, n. ${ }^{\circ} 2,177-198$ (2015). https://d oi.org/10.1093/jhuman/huv006

Leonardo Rodríguez, Análisis de la Justicia Restaurativa en materia de responsabilidad penal para adolescentes en Colombia, 22 Anuario de psicología jurídica, n. ${ }^{\circ}$ 1, 25-35 (2010). https://doi.org/10.5093/aj2012a3

Ley 1448 de 2011. Por la cual se dictan medidas de atención, asistencia y reparación integral a las víctimas del conflicto armado interno y se dictan otras disposiciones. 10 de junio de 2011. D. O. 48096. 
Ley 1820 de 2016. Por medio de la cual se dictan disposiciones sobre amnistía, indulto y tratamientos penales especiales y otras disposiciones. 30 de diciembre de 2016. D. O. 50102.

Ley 1922 de 2018. Por medio de la cual se adoptan unas reglas de procedimiento para la Jurisdicción Especial para la Paz. 18 de julio de 2018. D. O. 50658.

Ley 1957 de 2019. Estatutaria de la Administración de Justicia en la Jurisdicción Especial para la Paz. 6 de junio 2019. D. O. 50976.

Ley 906 de 2004. Por la cual se expide el Código de Procedimiento Penal. (Corregida de conformidad con el Decreto 2770 de 2004). 31 de agosto de 2004. D. O. 45658.

Ley 975 de 2005. por la cual se dictan disposiciones para la reincorporación de miembros de grupos armados organizados al margen de la ley, que contribuyan de manera efectiva a la consecución de la paz nacional y se dictan otras disposiciones para acuerdos humanitarios. 25 de julio de 2005. D. O. 45980.

Lode Walgrave, Investigating the Potentials of Restorative Justice Practice, 36 Journal of Law and Policy, 91-139 (2011). https://openscholarship.wustl.edu/law_journal_law_policy/vol36/iss1/6/

Luis Gutiérrez, La obligación internacional de investigar, juzgar y sancionar graves violaciones a los derechos humanos en contextos de justicia transicional, 16 Revista Estudios Socio-Jurídicos, n. ${ }^{\circ}$ 2, 23-60 (2014). http://dx.doi.org/10 $.12804 /$ esj16.02.2014.01

Margaret Urban, Restorative Justice and Reparations, 37 Journal of social philosophy, n. ${ }^{\circ}$ 3, 377-395 (2006). https:// doi.org/10.1111/j.1467-9833.2006.00343.x

María del Pilar Ahumada, La conciliación: un medio de justicia restaurativa. Análisis y reflexiones de su implementación en el delito de asistencia alimentaria en Colombia, 41 Revista de Derecho y Ciencias Políticas, n. ${ }^{\circ} 114,11-40$ (2010). https://revistas.upb.edu.co/index.php/derecho/article/view/1045

Michael Wenzel, Tyler G. Okimoto, Norman T. Feather \& Michael J. Platow, Retributive and Restorative Justice, 32 Law and Human Begavior, n. ${ }^{\circ}$ 5, 375-389 (2008). https://doi.org/10.1007/s10979-007-9116-6

Mónica Hurtado \& Catherine Pereira-Villa, Inserción labor adversa: otra cara del "demonio amorfo" de la trata de seres humanos, Cadernos Pagu, n. ${ }^{\circ}$ 53, 1-24 (2018). https://doi.org/10.1590/18094449201800530008

Mónica Hurtado, Ángela Iranzo Dosdad \& Sergio Gómez Hernández, The relationship between human trafficking and child recruitment in the Colombian armed conflict, 39 Third World Quarterly, n. ${ }^{\circ}$ 5, $941-958$ (2018). https://do i.org/10.1080/01436597.2017.1408404

Myra N. Blyth, Re-imagining restorative justice: The value of forgiveness, 5 Oxford Journal of Law, n. ${ }^{\circ}$ 1, 66-78 (2016). https://doi.org/10.1093/ojlr/rwv036

Naciones Unidas contra la Droga y el Delito, Manual sobre Programas de Justicia Restaurativa. Serie de manuales de justicia penal (2006).

Oficina del Alto Comisionado de las Naciones Unidas para los Derechos Humanos, Instrumentos del Estado de Derecho para sociedades que han salido de un conflicto, HR/PUB/08/1 (2008).

OIM. Culminan modelos de reintegración comunitaria en ocho regiones de Colombia. (2018). http://www.oim.org. co/news/culminan-modelos-de-reintegración-comunitaria-en-ocho-regiones-de-colombia

Olivia Lin, Demythologizing Restorative Justice: South Africa's Truth and Reconciliation Commission and Rwanda's Gacaca Courts in Context, 12 LSA Journal of International \& Comparative Law, n. ${ }^{\circ}$ 1, 41-85 (2005). https://n suworks.nova.edu/ilsajournal/vol12/iss1/2/

Organización de las Naciones Unidas 60/147, Principios y directrices básicos sobre el derecho de las víctimas de violaciones manifiestas de las normas internacionales de derechos humanos y de violaciones graves del derecho internacional humanitario a interponer recursos y obtener reparaciones, 16 de diciembre de 2005, https://www .ohchr.org/SP/ProfessionalInterest/Pages/RemedyAndReparation.aspx

Organización Internacional para las Migraciones Misión en Colombia, Spotlight - Prácticas y Justicia Restaurativa: un nuevo paradigma para el postconflicto en Colombia Parte II, 32, 1-4 (2019). https://colombia.iom.int/news/spo tlight-pr\%C3\%A1cticas-y-justicia-restaurativa-un-nuevo-paradigma-para-el-postconflicto-en 
Pablo de Greiff, Algunas reflexiones acerca del desarrollo de la Justicia Transicional, 1 Anuario de Derechos Humanos, n. ${ }^{\circ}$ 7, 17-39 (2011). https://doi.org/10.5354/0718-2279.2011.16994

Pacto Internacional de Derechos Civiles y Políticos, Res. A.G. 2200 A, ONU. Doc. A/RES/2200 (1996).

Patricia Lundy \& Mark McGovern, Whose justice? Rethinking transitional justice from the bottom up, 35, Journal of Law and Society, n. ${ }^{\circ}$ 2, 265-292 (2008). https://doi.org/10.1111/j.1467-6478.2008.00438.x

Ramya Krishnan, An Insight into the Importance of Restorative Justice and the Rights of Offenders: An Analysis of Issues of Convergence and Divergence; en Restorative Justice in India, 143-149 (R. Thilagaraj, ed., Springer, 2011). htt ps://doi.org/10.1007/978-3-319-47659-9_9

Rob White, Comunity Corrections and Restorative Justice, 16 Current Issues in Criminal Justice, n. ${ }^{\circ}$ 1, $42-56$ (2004). h ttp://www.austlii.edu.au/au/journals/CICrimJust/2004/11.pdf

Rodrigo Uprimny \& María P. Saffon, Justicia transicional y justicia restaurativa: tensiones y complementariedades, en Entre el perdón y el paredón: preguntas y dilemas de la justicia transicional, 211-232 (Angelika Rettberg, ed., Ediciones Uniandes, 2005). https://www.idrc.ca/sites/default/files/openebooks/190-6/index.html-page_211

Ruti Teitel, Transitional Justice Genealogy, 16 Harvard Human Rights Journal, n. ${ }^{\circ}$ 1, 69-94 (2003). http://www.qub. ac.uk/Research/GRI/mitchell-institute/FileStore/Filetoupload,697310,en.pdf

Shaily Anihotri \& Cassie Veach, Reclaiming Restorative Justice: An alternate Paradigm for Justice, 20 City University of New York Law Review, n. ${ }^{\circ}$ 2, 323-350 (2017). https://academicworks.cuny.edu/clr/vol20/iss2/3/

Spencer Zifcak, Restorativejustice in Timor-Leste: The Truth and Reconciliation Commission, 68 Development Bulletin, 51-54 (2005).

Stephen P. Garvey, 2003 Restorative Justice, Punishment and Atonement, Utah Law Review, n. ${ }^{\circ}$ 1, 303-317 (2003). h ttps://collections.lib.utah.edu/details?id=723036

Tony E. Marshall, Restorative Justice: An Overvierview (1.. ed., Information \& publications group, 1999). http://www .antoniocasella.eu/restorative/Marshall_1999-b.pdf

Tribunal Administrativo de Bolívar; Sala de lo Contencioso Administrativo. 5 de diciembre de 2002. 13001-23-31-000-2000-9001-01.

Tricia D. Olsen, Oayne Leigh \& Andrew G. Reiter, The Justice Balance: When Transitional Justice Improves Human Rights and Democracy, 32, Human Rights Quarterly, n. ${ }^{\circ}$ 4, 980-1007 (2010). http://www.ideaspaz.org/tools/d ownload/51147

Wendy Lambourne, Transitional Justice and Peacebuilding after Mass Violence, 3 The International Journal of Transitional Justice, n. ${ }^{\circ}$ 1, 28-48 (2007). https://doi.org/10.1093/ijtj/ijn037

William Wood \& Masahiro Suzuki, Four challenges in the future of restorative justice, 11 Victims \& Offender, n. 1 , 149-172 (2016). https://doi.org/10.1080/15564886.2016.1145610

Zvi D. Gabbay, Justifying Restorative Justice: A Theoretical Justification for the Use of Restorative Justice Practices, 2005, Journal of Dispute Resolution, n. ${ }^{\circ}$ 2, 349-397 (2005). https://scholarship.law.missouri.edu/jdr/vol2005/iss2/4/

\section{Notas}

[1] Acuerdo Final de Paz. Punto 5.1.2. Numeral 6; Ley 1957 de 2019, artículos 4 y 13; Ley 1922 de 2018, artículo 1.

[2] Corte Constitucional. Sentencia C-080/18.

[3] Ley 1957 de 2019, artículo 4.

[4] Acto Legislativo 01 de 2017, artículo 13; Ley 1957 de 2019, artículos 4, 127 y 142; Ley 1922 de 2018, artículo 1; Corte Constitucional, Sentencias C-674/17 y C-579/13.

[5] La reparación como finalidad de la justicia restaurativa ha sido destacada por los siguientes autores: Declan Roche, Restorative Justice and the Regulatory State in South African Townships, 42 British Journal of Criminology, n. ${ }^{\circ} 3,514-533$ (2002); Kieran McEvoy \& Harry Mika, Restorative Justice and the Critique, British Journal of Criminology, n. ${ }^{\circ} 4$, 534-562 (2002); Hennessey Hayez, Tara R. McGee, Helen Punter \& Michael J. Cerruto, Exploring the Implications of Agreements for Post-Conference Offending Behaviour, 54 British Journal of Criminology, n. ${ }^{\circ}$ 1, 109-127 (2014); Anna Eriksson, A bottom-Up approach to transformative justice in Northern Ireland, 3 International Journal of Transitional Justice, SSRN, n. ${ }^{\circ}$ 13, 301-320 (2009); Margaret Urban, Restorative Justice and Reparations, 37 Journal of social 
philosophy, n. 3 3 377-395 (2006); Grupo de Expertos sobre Justicia Restaurativa, Consejo Económico y Social, E/ CN.15/2002/5/Add.1 (2002).

[6] Acto Legislativo 01 de 2017, artículo 13; Ley 1957 de 2019, artículos 4, 127 y 142; Ley 1922 de 2018, artículo 1; Corte Constitucional, Sentencias C-674/17 y C-579/13.

[7] Corte Constitucional, Sentencias C-080/18, C-579/13, C-055/10 y C-979/05.

[8] Ver interpretación del principio de integralidad y de interdependencia de los mecanismos orientados a garantizar los derechos a la verdad, justicia, reparación y no repetición de las víctimas, en el capítulo 1.5.

[9] Acuerdo Final de Paz. Punto 5.1; Acto Legislativo 01 de 2017, artículo 1.

[10] Los siguientes autores han concebido tal articulación entre justiciar transicional y justiciar restaurativa: Laurel E. Fletcher \& Harvey M. Weinstein, Writing Transitional Justice: An Empirical Evaluation of Transitional Justice Scholarship in Academic Journals, 7 Journal of Human Rights Practice, n. ${ }^{\circ}$ 2, 177-198 (2015); Wendy Lambourne, Transitional Justice and Peacebuilding after Mass Violence, 3 The International Journal of Transitional Justice, n. ${ }^{\circ}$ 1, 28-48 (2007); Kieran McEvoy \& Harry Mika, Punishment, policing and praxis: Restorative justice and non\#violent alternatives to paramilitary punishments in Northern Ireland, 11 Policing and Society: An International Journal, n. 3-4, 359-382 (2011); James A. Sweeney, Restorative Justice and Transitional Justice at the ECHR, 12 International Criminal Law Review, n. ${ }^{\circ}$ 3, 313-338 (2012); Rodrigo Uprimny \& María P. Saffon, Justicia transicional y justicia restaurativa: tensiones y complementariedades, en Entre el perdón y el paredón: preguntas y dilemas de la justicia transicional, 211-232 (Angelika Rettberg, ed., Ediciones Uniandes, 2005).

[11] I Daniel W. Van, Restoring justice: an introduction to restorative justice, 5-256 (5.a ed., Routledge, 2014); I Gerry Johnstone, Restorative Justice: Ideas, Values, Debates, (2.a ed., Routledge, Londres, 2013); Tony E. Marshall, Restorative Justice: An overvierview, 5-33(1.a ed., Information \& publications group, 1999); I Gerry Johnstone \& Daniel W. Van, Handbook of Restorative Justice (1.a ed., William Publishing, 2007); Michael Wenzel, Tyler G. Okimoto, Norman T. Feather \& Michael J. Platow, Retributive and Restorative Justice, 32 Law and Human Begavior, n. ${ }^{\circ}$ 5, 375-389 (2008); Andrew Ashworth, Responsibilities, Rights and Restorative Justice, 42 The British Journal of Criminology, n. ${ }^{\circ}$ 3, 578-595(2002).

[12] Naciones Unidas contra la Droga y el Delito, Manual sobre Programas de Justicia Restaurativa. Serie de manuales de justicia penal (2006); Consejo Económico y Social de las Naciones Unidas, E/CN.15/2002/5/Add.1, Justicia restaurativa, Informe del Secretario General (2002); Heather Strang \& Laurence W. Sherman, Repairing the harm: Victims and Restorative Justice, 15 Utah Law Review, n. ${ }^{\circ}$ 1, 15-42 (2003); Stephen P. Garvey, 15 Restorative justice, punishment and atonement, Utah Law Review, n. ${ }^{\circ} 1,303-339$ (2003).

[13] Rodrigo Uprimny \& María P. Saffon, Justicia transicional y justicia restaurativa: tensiones y complementariedades, en Entre el perdón y el paredón: preguntas y dilemas de la justicia transicional, 211-232 (Angelika Rettberg, ed., Ediciones Uniandes, 2005); Johanna Shapland, Restorative justice: the views of victims and offenders, 3 Ministry of Justice Research Series, 7, 2-56 (2007); Karla Villareal, La víctima, el victimario y la justicia restaurativa, 7 Rivista di Criminología, Vittimologia e Sicurezza, n. ${ }^{\circ}$ 1, 43-57 (2013); Julio A. Sampedro, La justicia restaurativa: una nueva vía desde las víctimas en la solución al conflicto penal, 8 Interantional Law: Revista Colombiana de Derecho Internacional, n. ${ }^{\circ} 17,88-124$ (2010).

[14] Leonardo Rodríguez, Análisis de la Justicia Restaurativa en materia de responsabilidad penal para adolescentes en Colombia, 22 Anuario de psicología jurídica, n. ${ }^{\circ}$ 1, 25-35 (2010); Henry Vásquez \& Jairo Rojas, Tratamiento de la delincuencia juvenil en Colombia en el sistema de responsabilidad de adolescentes, Verba Iuris, n. ${ }^{\circ}$ 30, 115-133 (2013); María del Pilar Ahumada, La conciliación: un medio de justicia restaurativa. Análisis y reflexiones de su implementación en el delito de asistencia alimentaria en Colombia, 41 Revista de Derecho y Ciencias Políticas, n. ${ }^{\circ} 114,11-40$ (2010).

[15] Allison Morris \& Gabrielle Maxwell, Restorative Justice in New Zealand: Family Group Conferences as a Case Study, 1 Western Criminology Review, n. ${ }^{\circ}$ 1, 1-19 (1998); I Gerry Johnstone \& Daniel W. Van, Handbook of Restorative Justice (1.a ed., William Publishing, 2007); Kathleen Daly, Restorative justice and sexual assault: An archival study of the Court and conference cases, 46 British Journal of Criminology, n. ${ }^{\circ}$ 2, 334-354 (2005); Jeff Latimer, Dowden Craig \& Muise Danielle, The effectiveness of restorative justice practices: A meta-analysis, 85 The prison journal, $\mathrm{n} .{ }^{\circ} 2,127-144$ (2005).

[16] Ruti Teitel, Transitional Justice Genealogy, 16 Harvard Human Rights Journal, n. ${ }^{\circ}$ 1, 69-94 (2003); Oficina del Alto Comisionado de las Naciones Unidas para los Derechos Humanos, Instrumentos del Estado de Derecho para sociedades que han salido de un conflicto, HR/PUB/08/1 (2008); Consejo de Derechos Humanos, Informe del Relator Especial sobre la promoción de la verdad, la justicia, la reparación y garantías de no repetición, Pablo de Greiff, A/HRC/21/46 (2012); Corte Constitucional, Sentencia C-579/13.

[17] I Daniel W. Van, Restoring justice: an introduction to restorative justice, 5-256 (5.a ed., Routledge, 2014); I Gerry Johnstone, Restorative Justice: Ideas, Values, Debates, (2.a ed., Routledge, Londres, 2013); Tony E. Marshall, Restorative Justice: An overvierview, 5-33 (1.a ed., Information \& publications group, 1999); I Gerry Johnstone \& Daniel W. Van, Handbook of Restorative Justice (1.a ed., William Publishing, 2007). 
[18] Wendy Lambourne, Transitional Justice and Peacebuilding after Mass Violence, 3 The International Journal of Transitional Justice, n. ${ }^{\circ}$ 1, 28-48 (2007); Oficina del Alto Comisionado de las Naciones Unidas para los Derechos Humanos, Instrumentos del Estado de Derecho para sociedades que han salido de un conflicto, HR/PUB/08/1 (2008); Consejo de Derechos Humanos, Informe del Relator Especial sobre la promoción de la verdad, la justicia, la reparación y garantías de no repetición, Pablo de Greiff, A/HRC/21/46 (2012); Corte Constitucional. Sentencias C-674/17 y C-007/18.

[19] Allison Morris, Critiquing the critics: a brief response to critics of restorative justice, 42 British Journal of Criminology, 596-615 (2012); Annie Cossins, Restorative Justice and child sex offences: The theory and practice, 48 British Journal of Criminology, n. 3, 359-378 (2008); Rodrigo Uprimny \& María P. Saffon, Justicia transicional y justicia restaurativa: tensiones y complementariedades, en Entre el perdón y el paredón: preguntas y dilemas de la justicia transicional, 211-232 (Angelika Rettberg, ed., Ediciones Uniandes, 2005); Corte Constitucional, Sentencias C-979/05, C-055/10, C-080/18

[20] David Dyzenhaus, Judicial independence, Transitional Justice and the Rule of Law, 10 Otago Law Review, n. ${ }^{\circ} 4,345-370$ (2003); Patricia Lundy \& Mark McGovern, Whose justice? Rethinking transitional justice from the bottom up, 35, Journal of Law and Society, n. ${ }^{\circ}$ 2, 265-292 (2008); Tricia D. Olsen, Oayne Leigh \& Andrew G. Reiter, The justice balance: When transitional justice improves human rights and democracy, 32, Human Rights Quarterly, n. ${ }^{\circ}$ 4, 980-1011 (2010).

[21] Kerry Clamp \& Jonathan Doak, More than Words: Restorative Justice Concepts in Transitional Justice Settings, 12 International Criminal Law Review, n. ${ }^{\circ}$ 3, 339-360 (2012).

[22] Corte Constitucional, Sentencia C-080/18; Kerry Clamp \& Jonathan Doak, More than Words: Restorative Justice Concepts in Transitional Justice Settings, 12 International Criminal Law Review, n. ${ }^{\circ}$ 3, 339-360 (2012); Rodrigo Uprimny \& María P. Saffon, Justicia transicional y justicia restaurativa: tensiones y complementariedades, en Entre el perdón y el paredón: preguntas y dilemas de la justicia transicional, 211-232 (Angelika Rettberg, ed., Ediciones Uniandes, 2005).

[23] Gwen Robinson \& Joanna Shapland, Reducing recidivism: A task for restorative justice?, 48 British Journal of Criminology, n. 3 3 337-358 (2008); Michael Wenzel, Tyler G. Okimoto, Norman T. Feather \& Michael J. Platow, Retributive and Restorative Justice, 32 Law and Human Begavior, n. ${ }^{\circ}$ 5, 375-389 (2008); Andrew Ashworth, Responsibilities, Rights and Restorative Justice, 42 The British Journal of Criminology, n. ${ }^{\circ}$, 578-595 (2002).

[24] Naciones Unidas contra la Droga y el Delito. Manual sobre Programas de Justicia Restaurativa. Serie de manuales de justicia penal (2006); Consejo Económico y Social de las Naciones Unidas, E/CN.15/2002/5/Add.1, Justicia restaurativa, Informe del Secretario General (2002).

[25] Corte Constitucional. Sentencias C-674/17 y C-080/18.

[26] Rodrigo Uprimny \& María P. Saffon, Justicia transicional y justicia restaurativa: tensiones y complementariedades, en Entre el perdón y el paredón: preguntas y dilemas de la justicia transicional, 211-232 (Angelika Rettberg, ed., Ediciones Uniandes, 2005); Gina Rodríguez, Los limites del perdón. Notas sobre la justicia transicional en Sudáfrica, Centroamérica y Colombia, 151 Revista Justicia Juris, n. 2, 52-66 (2011); Alejandro Gómez \& Julián Correa, ¿Sobredimensión de la tensión entre justicia y paz? Reflexiones sobre justicia transicional, justicia penal y justicia restaurativa en Colombia, 13 International Law: Revista Colombiana de Derecho Internacional, n. ${ }^{\circ} 26,192-248$ (2015); Anna Eriksson, $A$ bottomUp approach to transformative justice in Northern Ireland, 3 International Journal of Transitional Justice, SSRN, n. ${ }^{\circ} 13$, 301-320 (2009); Organización Internacional para las Migraciones Misión en Colombia, Spotlight - Prácticas y Justicia Restaurativa: un nuevo paradigma para el postconflicto en Colombia Parte II, 32, 1-4 (2019).

[27] Wendy Lambourne, Transitional Justice and Peacebuilding after Mass Violence, 3 The International Journal of Transitional Justice, n. ${ }^{\circ}$ 1, 28-48 (2007); Corte Constitucional, Sentencia C-080/18.

[28] Anna Eriksson, A bottom-Up approach to transformative justice in Northern Ireland, 3 International Journal of Transitional Justice SSRN, n. ${ }^{\circ}$ 13, 301-320 (2009); Myra N. Blyth, Re-imagining restorative justice: The value of forgiveness, 5 Oxford Journal of Law, n. ${ }^{\circ}$ 1, 66-78 (2016); Kerry Clamp \& Jonathan Doak, More than Words: Restorative Justice Concepts in Transitional Justice Settings, 12 International Criminal Law Review, n. ${ }^{\circ}$ 3, 339-360 (2012); Corte Constitucional, Sentencia C-080/18.

[29] Declan Roche, Restorative Justice and the Regulatory State in South African Townships, 42 British Journal of Criminology, n. ${ }^{\circ}$ 3, 514-533 (2002).

[30] Si bien es cierto que previamente se había identificado como punto de convergencia entre la JR y la JT la búsqueda de la reconciliación y la reparación a las víctimas, se incluye a la 'centralidad de las víctimas y de las comunidades afectadas' y al 'diálogo como requisito del perdón' como valores que la JR aporta especialmente, por cuanto aquella se circunscribe al derecho penal \#un área a la que, como se señaló previamente, se le endilga el no brindar un rol preponderante a las víctimas\#. Por lo tanto, teniendo presente que una de las perspectivas de la JT se orienta a la rendición de cuentas y a la atribución de responsabilidad penal individual, la perspectiva de la JR resulta especialmente valiosa.

[31] Laurel E. Fletcher \& Harvey M. Weinstein, Writing Transitional Justice: An Empirical Evaluation of Transitional Justice Scholarship in Academic Journals, 7 Journal of Human Rights Practice, n. ${ }^{\circ}$ 2, 177-198 (2015); Wendy Lambourne, Transitional Justice and Peacebuilding after Mass Violence, 3 The International Journal of Transitional Justice, n. ○ 1, 28-48 (2007); Rodrigo Uprimny \& María P. Saffon, Justicia transicional y justicia restaurativa: tensiones y 
complementariedades, en Entre el perdón y el paredón: preguntas y dilemas de la justicia transicional, 211-232 (Angelika Rettberg, ed., Ediciones Uniandes, 2005).

[32] Consejo de Derechos Humanos, Informe del Relator Especial sobre la promoción de la verdad, la justicia, la reparación y garantías de no repetición, Pablo de Greiff, A/HRC/21/46 (2012); Corte Constitucional, Sentencia C-579/13; Luis Gutiérrez, La obligación internacional de investigar, juzgar y sancionar graves violaciones a los derechos humanos en contextos de justicia transicional, 16 Revista Estudios Socio-Jurídicos, n. 2 2, 23-60 (2014).

[33] Kieran McEvoy \& Harry Mika, Punishment, policing and praxis: Restorative justice and non-violent alternatives to paramilitary punishments in Northern Ireland, 11 Policing and Society: An International Journal, n. ${ }^{\circ}$ 3-4, 359-382 (2011); James A. Sweeney, Restorative Justice and Transitional Justice at the ECHR, 12 International Criminal Law Review, n. ${ }^{\circ}$ 3, 313-338 (2012).

[34] Janine N. Clark, The three Rs: retributive justice, restorative justice, and reconciliation, 11 Contemporary Justice Review, $\mathrm{n}$. '4,331-350 (2008); Olivia Lin, Demythologizing Restorative Justice: South Africa's Truth and Reconciliation Commission and Rwanda's Gacaca Courts in Context, 12 LSA Journal of International \& Comparative Law., n. ${ }^{\circ}$ 1, 41-85 (2005); Jennifer J. Llewellyn, Institutions for restorative justice: The South African truth and reconciliation commission, 49 The University of Toronto Law Journal, n. 3, 355-388 (1999); Spencer Zifcak, Restorative justice in Timor-Leste: The Truth and Reconciliation Commission, 68 Development Bulletin, 51-54 (2005).

[35] Acuerdo Final de Paz. Punto 5.1.2. Numeral 6; Ley 1957 de 2019, artículos 4 y 13; Ley 1922 de 2018 , artículo 1.

[36] Comisión de Derechos Humanos, Conjunto de principios actualizado para la protección y la promoción de los derechos humanos mediante la lucha contra la impunidad, E/CN.4/2005/102/Add.1 (2005); Organización de las Naciones Unidas 60/147, Principios y directrices básicos sobre el derecho de las víctimas de violaciones manifiestas de las normas internacionales de derechos humanos y de violaciones graves del derecho internacional humanitario a interponer recursos y obtener reparaciones, 16 de diciembre de 2005; Consejo de Derechos Humanos, Informe del Relator Especial sobre la promoción de la verdad, la justicia, la reparación y las garantías de no repetición, Pablo de Greiff, A/HRC/21/46 (2012); Caso de las Comunidades Afrodescendientes desplazadas de la Cuenca del Río Cacarica (Operación Génesis) vs. Colombia, Excepciones Preliminares, Fondo, Reparaciones y Costas, Corte I.D.H. (20 de noviembre de 2013); Caso Yarce y otras vs. Colombia, Excepción Preliminar, Fondo, Reparaciones y Costas, Corte I.D.H. (22 de noviembre de 2016); CIDH, Verdad, justicia y reparación: cuarto informe sobre la situación de derechos humanos en Colombia, OEA/ Ser.L/V/II, Doc. 49/13 (2013).

[37] Acto Legislativo 01 de 2017; Ley 1957 de 2019.

[38] Es importante precisar que la aproximación del derecho a la reparación se delimitará a su aplicación en escenarios de justicia transicional. De ahí que se acuda a fuentes circunscritas específicamente a estos contextos.

[39] Hennessey Hayez, Tara R. McGee, Helen Punter \& Michael J. Cerruto, Exploring the Implications of Agreements for PostConference Offending Behaviour, 54 British Journal of Criminology, n. 1, 109-127 (2014); William Wood \& Masahiro Suzuki, Four challenges in the future of restorative justice, 11 Victims \& Offender, n. ${ }^{\circ}$ 1, 149-172 (2016); Kathleen Daly, What is Restorative Justice? Fresh answers to a vexed question, 11 Victims \& offenders, n. ${ }^{\circ}$ 1, 9-29.

[40] Andrew Bottoms, Some sociological reflections on restorative justice, en Restorative juvenile justice and criminal justice: Competing or reconcilable paradigms?, 79-114 (A. von Hirsch A., J. Roberts J., A. Bottoms A., K. Roach K. \& M. Schiff M., Edseds., Criminal Justice Press, New York, (2003); Shaily Anihotri \& Cassie Veach, Reclaiming Restorative Justice: An alternate Paradigm for Justice, 20 City University of New York Law Review, n. ${ }^{\circ}$ 2, 323-350 (2017).

[41] John Braithwaite, The fundamentals of restorative justice, en A kind of mending: Restorative Justice in the Pacific Islands, 35-43 (Sinclair Dinnen, ed., ANU Press, 2010); Ezzat Fattah, Some reflections on the paradigm of restorative justice and its viability for juvenile justice, en Restorative justice for juveniles: Potentialities, risks and problems, 389-401 (Lode Walgrave, ed., Leuven University Press, 1998). Ver también: Ley 906 de 2004. Por la cual se expide el Código de Procedimiento Penal de Colombia. Artículo 518

[42] George Mousourakis, Understanding and implementing restorativejustice, 11 Tilburg Foreign Law Review, n..$^{\circ}$ 3, 626-652 (2003); Allison Morris \& Gabrielle Maxwell, Restorative Justice in New Zealand: Family Group Conferences as a Case Study, 1 Western Criminology Review, n. ${ }^{\circ}$ 1, 1-19 (1998); Declan Roche, Restorative Justice and the Regulatory State in South African Townships, 42 British Journal of Criminology, n. ${ }^{\circ}$ 3, 514-533 (2002).

[43] Anna Eriksson, A Bottom-Up approach to Transformative Justice in Northern Ireland, 3 International Journal of Transitional JusticeSSRN, n. ${ }^{\circ} 13,301-320$ (2009); Myra N. Blyth, Re-imagining restorative justice: The value of forgiveness, 5 Oxford Journal of Law, n. ${ }^{\circ}$ 1, 66-78 (2016); Kerry Clamp \& Jonathan Doak, More than Words: Restorative Justice Concepts in Transitional Justice Settings, 12 International Criminal Law Review, n. ${ }^{\circ}$ 3, 339-360 (2012); Corte Constitucional, Sentencia C-080/18.

[44] Naciones Unidas contra la Droga y el Delito, Manual sobre Programas de Justicia Restaurativa (2006).

[45] Rob White, Comunity corrections and restorative justice, 16 Current Issues Crim. Just, n. ${ }^{\circ}$ 1, $42-56$ (2004); Lode Walgrave, Investigating the Potentials of Restorative Justice Practice, 36 Journal of Law and Policy, 91-139 (2011); Katherine Basire, 13 Taking Restorative Justice Seriously, 13 Canterbury Law Review, n. ${ }^{\circ}$, 31-57 (2007); Zvi D. Gabbay, 
Justifying Restorative Justice: A Theoretical Justification for the Use of Restorative Justice Practices, 1, Journal of Dispute Resolution, $n .^{\circ}$ 2, 349-397 (2005).

[46] Diane Sivasubramaniam, A special issue on restorative justice: unravelling the mystery, 20 Critical Criminology, 1-7 (2012); Ramya Krishnan, An Insight into the Importance of Restorative Justice and the Rights of Offenders: An Analysis of Issues of Convergence and Divergence; en Restorative Justice in India, 143-149 (R. Thilagaraj, ed., Springer, 2011).

[47] I Gerry Johnstone \& Daniel W. Van, Handbook of Restorative Justice (1.a ed., William Publishing, 2007); I Daniel W. Van, Restoring justice: an introduction to restorative justice, 5-256 (5.a ed., Routledge, 2014); I Gerry Johnstone, Restorative Justice: Ideas, Values, Debates, (2.a ed., Routledge, Londres, 2013); Tony E. Marshall, Restorative Justice: An overvierview, 5-33 (1.a ed., Information \& publications group, 1999).

[48] Consejo de Derechos Humanos, Informe del Relator Especial sobre la promoción de la verdad, la justicia, la reparación y las garantías de no repetición, Pablo de Greiff, A/HRC/21/46 (2012); Caso Masacres de El Mozote y lugares aledaños vs. El Salvador. Fondo, Reparaciones y Costas, Corte I.D.H. (25 de octubre de 2012); Caso Gelman vs. Uruguay. Fondo y Reparaciones, Corte I.D.H. (24 de febrero de 2011); CIDH, Verdad, justicia y reparación: cuarto informe sobre la situación de derechos humanos en Colombia, OEA/Ser.L/V/II, Doc. 49/13 (2013).

[49] Asamblea General de las Naciones Unidas, Promoción de la verdad, la justicia, la reparación y las garantías de no repetición, Informe del Relator Especial sobre la promoción de la verdad, la justicia, la reparación y las garantías de no repetición, Pablo de Greiff, A/69/518 (2014); Caso Yarce y otras vs. Colombia, Excepción Preliminar, Fondo, Reparaciones y Costas, Corte I.D.H. (22 de noviembre de 2016); CIDH, Verdad, justicia y reparación: cuarto informe sobre la situación de derechos humanos en Colombia, OEA/Ser.L/V/II, Doc. 49/13 (2013); Corte Constitucional. Sentencias C-052/12, C-771/11, C-936/10.

[50] Asamblea General de las Naciones Unidas, Promoción de la verdad, la justicia, la reparación y las garantías de no repetición, Informe del Relator Especial sobre la promoción de la verdad, la justicia, la reparación y las garantías de no repetición, Pablo de Greiff, A/69/518 (2014).

[51] Comisión de Derechos Humanos, Conjunto de principios actualizado para la protección y la promoción de los derechos bumanos mediante la lucha contra la impunidad, E/CN.4/2005/102/Add.1 (2005); Organización de las Naciones Unidas 60/147, Principios y directrices básicos sobre el derecho de las víctimas de violaciones manifiestas de las normas internacionales de derechos humanos y de violaciones graves del derecho internacional humanitario a interponer recursos $y$ obtener reparaciones, 16 de diciembre de 2005; CIDH, Verdad, justicia y reparación: cuarto informe sobre la situación de derechos humanos en Colombia, OEA/Ser.L/V/II, Doc. 49/13 (2013); Corte Constitucional, Sentencias C-007/18, C-080/18, T-130/16, T-174/16, T-197/15, T-037/15, C-694/15, C-795/14, C-286/14, C-180/14, SU-254/13, C-280/13, C-715/12.

[52] Caso Villaseñor Velarde y otros vs. Guatemala, Fondo, Reparaciones y Costas, Corte I.D.H. (5 de febrero de 2019); Caso Colindres Schonenberg vs. El Salvador, Fondo, Reparaciones y Costas, Corte I.D.H. (4 de febrero de 2019). Caso Órdenes Guerra y otros vs. Chile, Fondo, Reparaciones y Costas, Corte I.D.H. (29 de noviembre de 2018).

[53] Asamblea General de las Naciones Unidas, Promoción de la verdad, la justicia, la reparación y las garantías de no repetición, Informe del Relator Especial sobre la promoción de la verdad, la justicia, la reparación y las garantías de no repetición, Pablo de Greiff, A/69/518 (2014).

[54] Asamblea General de las Naciones Unidas, Promoción de la verdad, la justicia, la reparación y las garantías de no repetición, Informe del Relator Especial sobre la promoción de la verdad, la justicia, la reparación y las garantías de no repetición, Pablo de Greiff, A/69/518 (2014); Corte Constitucional, Sentencias C-694/15, T-234/12; C-233/16.

[55] Consejo de Derechos Humanos, Informe del Relator Especial sobre la promoción de la verdad, la justicia, la reparación y las garantías de no repetición, Pablo de Greiff, A/HRC/21/46 (2012); Caso de las Comunidades Afrodescendientes desplazadas de la Cuenca del Río Cacarica (Operación Génesis) vs. Colombia, Excepciones Preliminares, Fondo, Reparaciones y Costas, Corte I.D.H. (20 de noviembre de 2013); Caso Yarce y otras vs. Colombia, Excepción Preliminar, Fondo, Reparaciones y Costas, Corte I.D.H. (22 de noviembre de 2016); CIDH, Verdad, justicia y reparación: cuarto informe sobre la situación de derechos humanos en Colombia, OEA/Ser.L/V/II, Doc. 49/13 (2013).

[56] A pesar de que, como se señaló previamente, el rol del victimario varía en cada uno de los paradigmas. En la justicia restaurativa tiene un papel más preponderante, mientras que, en el marco de la garantía del derecho a la reparación, su participación usualmente se circunscribe en la implementación de medidas orientadas a remediar el daño causado a las víctimas.

[57] Acto Legislativo 01 de 2017, artículo transitorio 1; Ley 1957 de 2019, artículo 4; Ley 1922 de 2018, artículo 1; Corte Constitucional, Sentencia C-080/18.

[58] Acto Legislativo 01 de 2017, artículo transitorio 5; Ley 1957 de 2019, artículos 2 y 8; Ley 1922 de 2018, artículo 1.

[59] Acto Legislativo 01 de 2017, artículo transitorio 1; Ley 1957 de 2019, artículos 4, 13, 127 y 143; Ley 1922 de 2018 , artículo 1; Corte Constitucional, Sentencias C-579/13; C-674/17 y C-080/18.

[60] Acto Legislativo 01 de 2017, artículo transitorio 1 y Ley 1957 de 2019, artículo 13; Corte Constitucional, Sentencia C-080/18; 
[61] Ley 1957 de 2019, artículo 4 y Corte Constitucional, Sentencia C-080/18;

[62] Ley 1957 de 2019, artículo 4; Ley 1922 de 2018, artículo 1; Corte Constitucional, Sentencia C-674/17.

[63] Corte Constitucional, Sentencia C-080/18.

[64] Ley 1922 de 2018, artículos 1 y 27 y Corte Constitucional, Sentencia C-674/17.

[65] Acto Legislativo 01 de 2017, artículo transitorio 1; Ley 1957 de 2019, artículos 4, 13, 127 y 143; Ley 1922 de 2018, artículo 1; Corte Constitucional, Sentencias C-579/13; C-674/17 y C-080/18.

[66] Acto Legislativo 01 de 2017, artículo transitorio 1 y Ley 1957 de 2019, artículo 13; Corte Constitucional, sentencia C-080/18.

[67] JEP. Sala de Definición de Situaciones Jurídicas. Resolución diciembre de 2018. Compareciente: Henry William Torres Escalante.

[68] Ley 1957 de 2019, artículo 13 y Corte Constitucional, Sentencia C-080/18.

[69] Ley 1957 de 2019, artículo 143 y Ley 1922 de 2018, parágrafo del artículo 27 y artículo 65.

[70] Ley 1922 de 2018, Artículo 27C.

[71] Ley 1922 de 2018, Artículo 44.

[72] Ley 1922 de 2018, Artículo 48.

[73] Ley 1922 de 2018, Artículo 27.

[74] Ley 1922 de 2018, Artículo 3.

[75] Ley 1957 de 2019. Artículo 79.

[76] Ley 1922 de 2018, Artículo 33.

[77] Ley 1922 de 2018, Artículo 38A.

[78] Ley 1957 de 2019. Artículo 129.

[79] Acto Legislativo 01 de 2017, artículo 1 y Corte Constitucional, Sentencia C-674 de 2017.

[80] Ley 1820 de 2016, artículo 14.

[81] En el caso de las FARC, la Ley Estatutaria, en el artículo 20, dispone como condiciones i) la entrega de niños, niñas y adolescentes; ii) la entrega de armas y iii) la participación en el proceso de reintegración a la vida civil. Corte Constitucional. Sentencias C-579/13, C-674/17 y C-007/18.

[82] Acuerdo de paz. Punto 5.13; Acto Legislativo 01 de 2017, artículo 5; Ley Estatutaria, artículo 20; Ley de amnistía, artículos $14,33,35$ y 50 .

[83] Ley de amnistía, artículos 14, 33, 35 y 50.

[84] Acto Legislativo 01 de 2017, artículo 5. Ley de amnistía, artículos 14 y 33.

[85] Acto Legislativo 01 de 2017, artículo 5. Ley de amnistía, artículo 50.

[86] Acto Legislativo 01 de 2017, artículo 17.

[87] Ley de amnistía, artículo 14 y Corte Constitucional de Colombia. Sentencia C-007 de 2018 (M. P. Diana Fajardo Rivera; 1 de marzo de 2018).

[88] Acuerdo de paz. Punto 5.13; Acto Legislativo 01 de 2017, artículo 5; Ley Estatutaria, artículo 20; Ley de amnistía, artículos $14,33,35$ y 50 .

[89] Ley 1922 de 2018, artículo 68 y Corte Constitucional de Colombia. Sentencia C-007 de 2018 (M. P. Diana Fajardo Rivera; 1 de marzo de 2018).

[90] Ley 1922 de 2018, artículo 68.

[91] Corte Constitucional. Sentencias C-007/18 y C-674/17.

[92] Acto Legislativo 01 de 2017, artículo transitorio 1; Ley 1957 de 2019, artículo 4; Ley 1922 de 2018, artículo 1; Corte Constitucional, Sentencia C-080/18.

[93] JEP. Tribunal para la Paz. Sección de apelación. Auto TP-SA 19 de 2018. 21 de agosto de 2018.

[94] JEP. Sala de Definición de Situaciones Jurídicas. Resolución diciembre de 2018. Compareciente: Henry William Torres Escalante.

[95] JEP. SRVR. Auto No. 060. 5 de octubre de 2018. Caso 001.

[96] JEP. Sala de definición de situaciones jurídicas. Subsala séptima. Resolución 0035 de 2019. Compareciente: Willinton de Jesús Graciano Sepúlveda; Tribunal para la Paz. Sección de Revisión. SRT-AR-003/2018. 24 de octubre de 2018. Jorge Eliécer Plazas Acevedo; Sala de definición de situaciones jurídicas. Subsala sexta. Resolución 1941 de 2019. Compareciente: José Gregorio Hernández.

[97] Acto Legislativo 01 de 2017, artículo transitorio 13; Ley 1957 de 2019, artículos 127, 128, 140; Ley 1922 de 2018, artículos 1 y 65.

[98] Ley 1957 de 2019, artículos 127 y 128.

[99] Ley 1957 de 2019, artículo 143.

[100] Ley 1957 de 2019, artículo 143; Ley 1922 de 2018, artículo 65 y parágrafo del artículo 27.

[101] Ley 1957 de 2019, artículo 143; Ley 1922 de 2018, artículo 65 y parágrafo del artículo 27.

[102] Ley 1922 de 2018, artículo 65. 
[103] Ley 1957 de 2019, artículo 143

[104] Ley 1922 de 2018, artículo 29.

[105] Ley 1922 de 2018, artículo 30.

[106] Corte Constitucional, Sentencia C-080/18.

[107] Acto Legislativo 01 de 2017, artículos transitorios 1, 5 y 18; Ley 1957 de 2019, artículos 7, 13, 15 y 18; Ley 1922 de 2018, artículos 1 y 65; Ley 1448 de 2011, artículos 1, 2, 25 y 27; Corte Constitucional, Sentencias C-080/18, C-280/13, C-820/12, C-715/12, C-253A/12, C-370/06.

[108] Corte Constitucional, Sentencias T-083/17 y SU-254/13.

[109] Acto Legislativo 01 de 2017, artículo transitorio 18; Ley 1957 de 2019, artículos 7, 38.

[110] Acto Legislativo 01 de 2017, artículos transitorios 18

[111] Ley 1957 de 2019, artículos 13, 18

[112] Acto Legislativo 01 de 2017, artículos transitorios 18

[113] Ley 1448 de 2011, artículo 25.

[114] Íd.

[115] Acto Legislativo 01 de 2017, artículos transitorios 5; Ley 1957 de 2019, artículos 20, $39,52$.

[116] Acto Legislativo 01 de 2017, artículos transitorios 1 y 13; Ley 1957 de 2019, artículos 13, 38, 39, 127, 128,

[117] Ley 1957 de 2019, artículo 143.

[118] Acuerdo de paz. Punto 5.13; Acto Legislativo 01 de 2017, artículo 5; Ley Estatutaria, artículo 20; Ley de amnistía, artículos 14, 33, 35 y 50.

[119] Ley de amnistía, artículos 14, 33, 35 y 50.

[120] Corte Constitucional, Sentencia C-080/18.

[121] Acuerdo de paz. Punto 5.13; Acto Legislativo 01 de 2017, artículo 5; Ley Estatutaria, artículo 20; Ley de amnistía, artículos 14, 33, 35 y 50; JEP. SRVR. Auto No. 060, 5 de ocrubre de 2018; Tribunal para la Paz. Sección de Apelación. Auto TP-SA 19 de 2018, 21 de agosto de 2018. Compareciente: David Char Navas.

[122] El deber de indemnización de los terceros y civiles será definido por la jurisdicción ordinaria, de acuerdo con la Corte Constitucional, Sentencia C-080/18.

[123] Corte Constitucional, Sentencia C-080/18.

[124] Íd.

[125] Ley 1957 de 2019, artículo 13 y Corte Constitucional, Sentencia C-080/18.

[126] Ley 1448 de 2011.

[127] Ley 975 de 2005, artículos 11D, 15, 17.

[128] Ley 975 de 2005, artículo 23.

[129] Ley 975 de 2005, artículo 24.

[130] Corte Suprema de Justicia, Auto interlocutorio (M. P. Gustavo Enrique Malo Fernández; 16 de marzo de 2007).

[131] JEP. Tribunal para la Paz. Sección de apelación. Auto TP-SA 123 de 2019.

[132] Constitución Política de Colombia, artículo 90; Consejo de Estado, Sala de lo Contencioso Administrativo, Sección tercera, Sentencia 54001-23-31-000-1996-09890-01(21660), 29 de febrero de 2012, 21.660); Sala Plena de los Contencioso Administrativo, 13 de marzo del 2018, 28.769.

[133] Consejo de Estado, Sala de lo Contencioso Administrativo, Sala Plena, Sección Tercera, 28 de agosto de 2014, 32.888; Consejo de Estado, Sala de lo Contencioso Administrativo, Sección tercera, Subsección B, Sentencia 2000-03838, 22 de abril de 2015, 19.146; Sala de lo Contencioso Administrativo, Sección primera, 29 de abril de 2010, 37.501.

[134] Corte Constitucional. Sentencia C-080/18; Ley 1957 de 2019, artículos 3, 32, 62 y 63.

[135] Consejo de Estado, Intervención ante el Congreso de la República sobre la Jurisdicción Especial para la Paz (2016).

[136] Por ejemplo, casos de la Unión Patriótica o de Falsos positivos. Cfr. Consejo de Estado, Sala de lo Contencioso Administrativo, Sección tercera, subsección B, Sentencia 2011-00096, 30 de noviembre de 2017,46.567; Consejo de Estado, Sala de lo Contencioso Administrativo, Sección tercera, subsección C, Sentencia 85001-23-31-000-2010-00178-01 (47671), 7 de septiembre de 2015, 47.671.

[137] Corte Constitucional, Sentencia C-080/18.

[138] Consejo de Estado, Sala de lo Contencioso Administrativo. 15 de agosto de 2007. 190012331000200300385-01; Tribunal Administrativo de Bolívar; Sala de lo Contencioso Administrativo. 5 de diciembre de 2002. 13001-23-31-000-2000-9001-01.

[139] Corte Suprema de Justicia. Sala de Casación Penal. Proceso No. 19044 (M. P. Edgar Lombana Trujillo; 12 de noviembre de 2003).

[140] Ver artículo 27C de la Ley 1922 de 2018.

[141] La experiencia en Ruanda resulta muy ilustradora. En la concepción tradicional de los Tribunales Gacaca, los inyangamugayo -ancianos- actuaban únicamente como mediadores. Pero, con su transformación, tras la creación del Tribunal Penal para Ruanda, este rol se transformó al de verdaderos ‘jueces'. Autores como Karen Domínguez y Tatiana 
Rosero indican que con su transformación se perdió la teleología reparadora y reconciliadora con la que se había concebido el sistema. Karen G. Domínguez \& Tatiana A. Rosero, Justicia sobre la bierba. Tribunales Gacaca, lecciones de reconciliación para Colombia, Estudios Políticos, n. ${ }^{\circ}$ 51, 218-239.

[142] I Howard Zehr, El pequeño libro de la Justicia Restaurativa 55-81 (1.a ed., Good Books, 2010); Kieran McEvoy, Harry Mika \& Barbara Hudon, Introduction: Practice, Performance and Prospects for Restorative Justice, 42 The British Journal of Criminology, n. 3 3, 469-475 (2002); Declan Roche, Restorative Justice and the Regulatory State in South African Townships, 42 British Journal of Criminology, n. ${ }^{\circ} 3,514-533$ (2002).

[143] Corte Constitucional, Sentencia C-080/18.

[144] Collen Murphy, Judging the Justice of the Colombian Final Agreement, 1-13 (Working Paper, 2019); David Dyzenhaus \& Alma Diamond, The Resilient Constitution, 1-19 (Corte Constitucional de Colombia, Working Paper, 2019); Pablo de Greiff, Algunas reflexiones acerca del desarrollo de la Justicia Transicional, 1 Anuario de Derechos Humanos, n. 7 , $17-39$ (2011).

[145] Andrew Ashworth, Responsibilities, Rights and Restorative Justice, 42 The British Journal of Criminology, n. ${ }^{\circ} 3,578-595$ (2002); Andrew Ashworth, Is Restorative Justice the Way Forward for Criminal Justice? 54 Current legal problems, n. ${ }^{\circ}$ 1, 347-376 (2001); John Braithwaite, Setting Standards for Restorative Justice, 42 The British Journal of Criminology, n. ${ }^{\circ} 3,563-577$ (2002).

[146] Convención do Belém do Pará, Organización de estados americanos (1994); Fernández Ortega y otros vs. México, Excepción preliminar, fondo, reparaciones y costas, Corte I.D.H. (30 de agosto de 2010); Caso Rosendo Cantú y Otra vs. México, Excepción Preliminar, Fondo, Reparaciones y Costas, Corte I.D.H. (15 de mayo de 2010).

[147] IFIT, Los debates de La Habana: una mirada desde adentro (1.a ed., Andrés Bermúdez, ed., 2018).

[148] Ley 1957 de 2019. Artículo 114.14: "El Secretario Ejecutivo ejercerá las siguientes funciones transitorias y permanentes: (...) Coordinar con las demás entidades y organismos públicos las acciones para garantizar a las víctimas y a los procesados el acceso a la justicia, la participación, la defensa, la comparecencia, la representación judicial, la seguridad y el cumplimiento de la justicia restaurativa" Cfr. Ley 1957 de 2019. Parágrafo, artículo 14.

[149] Ver, por ejemplo, la Sala de Justicia y Paz, creada al interior de la Unidad para la atención y reparación integral a las víctimas, con un mandato definido tanto en el marco del incidente de reparación integral como en la materialización de las órdenes proferidas en sentencias ejecutoriadas.

[150] Ley 1957 de 2019. Artículo 112.12.

[151] Consejo de Estado, Sala de lo Contencioso Administrativo, Sección tercera-Subsección B, 30 de noviembre de 2017, 46567: En la sentencia, el Consejo de Estado, como medida de satisfacción, remitió el expediente a la JEP, para que (i) se estudie la posibilidad de avocar conocimiento sobre los hechos de la Sentencia; (ii) declarar la configuración de un crimen de lesa humanidad y (iii) coordinar todos los mecanismos del SIVJRNR a fin de reparar integralmente a las víctimas; Sala de lo Contencioso Administrativo, sección tercera, subsección B, 14 de febrero de 2018, 52616: El Consejo de Estado, como medida de satisfacción, exhorta a la Presidencia de la Corporación para que establezca en la página web un enlace que contenga su jurisprudencia relacionada con el conflicto armado colombiano, para asegurar el eventual conocimiento de estos casos por parte de la JEP.

[152] Consejo de Estado, Sala de lo Contencioso Administrativo. Sección tercera - Subsección B. 10 de mayo de 2018. 15001-23-31-000-2007-00694-01: El Consejo de Estado, como garantía de no repetición, exhortó a la JEP "para que estudie la posibilidad de avocar la competencia del presente asunto".

[153] Ver por ejemplo, Mónica Hurtado \& Catherine Pereira-Villa, Inserción labor adversa: otra cara del "demonio amorfo" de la trata de seres humanos, Cadernos Pagu, n. ${ }^{\circ}$ 53, 1-24 (2018); Mónica Hurtado, Ángela Iranzo Dosdad \& Sergio Gómez Hernández, The relationship between human trafficking and child recruitment in the Colombian armed conflict, 39 Third World Quarterly, n. ${ }^{\circ}$ 5, 941-958 (2018); Rodrigo Uprimny \& María P. Saffon, Justicia transicionaly justicia restaurativa: tensiones y complementariedades, en Entre el perdón y el paredón: preguntas y dilemas de la justicia transicional, 211-232 (Angelika Rettberg, ed., Ediciones Uniandes, 2005); Collen Murphy, Judging the Justice of the Colombian Final Agreement, 1-13 (Working Paper, 2019); Iván Orozco, La posguerra colombiana: Divagaciones sobre la venganza, la justicia y la reconciliación, Análisis Político, n. ${ }^{\circ} 46,214-242$ (2002).

[154] Ver, por ejemplo: OIM. Culminan modelos de reintegración comunitaria en ocho regiones de Colombia (2018).

[155] ARN. A través de obra de teatro, la ARN construye reconciliación en Cundinamarca. (20 de noviembre, 2017); ARN. Obra de teatro depersonas desmovilizadas y niños con discapacidad cognitiva estará en la clausura de las Olimpiadas FIDES. (12 de junio, 2015).; ARN. Noche de música, baile y narrativas, al cierre de iniciativa de jóvenes en reintegración en Bucaramanga. (1 de diciembre, 2017).

[156] ARN. Tejiendo sueños a través de la música. (30 de junio, 2016).

[157] ARN. "Con disciplina se materializan los sueños": Diego Saldarriaga. (15 de septiembre, 2017).)

[158] ARN. La danza árabe como herramienta de reconciliación y liderazgo de la mujer. (7 de abril, 2017).

[159] ARN. Reconciliémonos a través del arte. (8 de noviembre, 2017). 
Juana Acosta-López, et al. Justicia restaurativa y reparación: desafíos de la JEP frente a una...

* $\quad$ Artículo de reflexión

Licencia Creative Commons CC BY 4.0

Cómo citar este artículo: Juana Acosta-López \& Cindy Vanessa Espitia Murcia, Justicia restaurativa y reparación: desafios de la JEP frente a una relación en construcción, 69 Vniversitas (2020). https://doi.org/1 $0.11144 /$ Javeriana.vj69.jrrd 